\title{
The Critical Importance of Old World Fruit Bats for Healthy Ecosystems and Economies
}

\author{
Sheema Abdul Aziz'*, Kim R. McConkey², Krizler Tanalgo 3,4, Tuanjit Sritongchuay ${ }^{3}$, \\ Mary-Ruth Low ${ }^{1}$, Joon Yee Yong ${ }^{1}$, Tammy L. Mildenstein ${ }^{5}$, Christine Ely Nuevo-Diego ${ }^{6}$, \\ Voon-Ching Lim ${ }^{7}$ and Paul A. Racey ${ }^{8}$

\begin{abstract}
${ }^{1}$ Project Pteropus, Rimba, Kuala Lumpur, Malaysia, ${ }^{2}$ School of Environmental and Geographical Sciences, University of Nottingham Malaysia, Semenyih, Malaysia, ${ }^{3}$ Landscape Ecology Group, Center for Integrative Conservation, Xishuangbanna Tropical Botanical Garden, Chinese Academy of Sciences, Menglun, China, ${ }^{4}$ Department of Biological Sciences, College of Science and Mathematics, University of Southern Mindanao, Cotabato, Philippines, ${ }^{5}$ Department of Biology, Cornell College, Mount Vernon, IA, United States, ${ }^{6}$ Bat Eco-Interactions Project, Houston, TX, United States, ${ }^{7}$ School of Science, Monash University Malaysia, Bandar Sunway, Malaysia, ${ }^{8}$ Centre for Ecology and Conservation,
\end{abstract} \\ University of Exeter, Exeter, United Kingdom
}

OPEN ACCESS

Edited by:

Anna Traveset,

Consejo Superior de Investigaciones Científicas, Spain

Reviewed by:

Ricardo Rocha,

University of Cambridge,

United Kingdom

Merlin Tuttle,

Merlin Tuttle's Bat Conservation,

United States

*Correspondence:

Sheema Abdul Aziz

sheema@rimbaresearch.org

Specialty section:

This article was submitted to

Population and Evolutionary

Dynamics,

a section of the journal

Frontiers in Ecology and Evolution

Received: 14 December 2020

Accepted: 08 March 2021

Published: 06 April 2021

Citation:

Aziz SA, McConkey KR,

Tanalgo K, Sritongchuay T, Low M-R,

Yong $J Y$, Mildenstein $T L$,

Nuevo-Diego CE, Lim VC and

Racey PA (2021) The Critical Importance of Old World Fruit Bats for Healthy Ecosystems and Economies.

Front. Ecol. Evol. 9:641411. doi: 10.3389/fevo.2021.641411
Despite extensive documentation of the ecological and economic importance of Old World fruit bats (Chiroptera: Pteropodidae) and the many threats they face from humans, negative attitudes towards pteropodids have persisted, fuelled by perceptions of bats as being pests and undesirable neighbours. Such long-term negativity towards bats is now further exacerbated by more recent disease-related concerns, particularly associated with the current COVID-19 pandemic. There remains an urgent need to investigate and highlight the positive and beneficial aspects of bats across the Old World. While previous reviews have summarised these extensively, numerous new studies conducted over the last 36 years have provided further valuable data and insights which warrant an updated review. Here we synthesise research on pteropodid-plant interactions, comprising diet, ecological roles, and ecosystem services, conducted during 19852020. We uncovered a total of 311 studies covering 75 out of the known 201 pteropodid species (37\%), conducted in 47 countries. The majority of studies documented diet (52\% of all studies; 67 pteropodid species), followed by foraging movement (49\%; 50 pteropodid species), with fewer studies directly investigating the roles played by pteropodids in seed dispersal (24\%; 41 pteropodid species), pollination (14\%; 19 pteropodid species), and conflict with fruit growers (12\%; 11 pteropodid species). Pteropodids were recorded feeding on 1072 plant species from 493 genera and 148 families, with fruits comprising the majority of plant parts consumed, followed by flowers/nectar/pollen, leaves, and other miscellaneous parts. Sixteen pteropodid species have been confirmed to act as pollinators for a total of 21 plant species, and 29 pteropodid species have been confirmed to act as seed dispersers for a total of 311 plant species. Anthropogenic threats disrupting bat-plant interactions in the Old World include hunting, direct persecution, habitat loss/disturbance, invasive species, and climate change, leading to ecosystem-level repercussions. We identify notable research gaps and important research priorities to support conservation action for pteropodids.

Keywords: bat-plant interactions, double mutualism, ecosystem services, Palaeotropics, pollination, Pteropodidae, seed dispersal 


\section{INTRODUCTION}

Discrepancies between human perceptions of an animal, and the importance of the animal to broader human well-being, is perhaps most profoundly unbalanced for bats. Old World fruit bats (family Pteropodidae; Simmons and Cirranello, 2020; also referred to as "pteropodids") are particularly threatened, facing multiple environmental pressures not only as a result of exclusion from statutory protection policies, but also due to a lack of necessary conservation attention, even for legally protected species (Aziz et al., 2016). In addition, the COVID19 pandemic is the latest and worst disease-related concern to have reinforced long-held fears and negative attitudes towards bats (López-Baucells et al., 2018; Rocha et al., 2020; Tuttle, 2020; Zhao, 2020). Bats are persecuted due to misguided fears of viral transmission (Tuttle, 2018; Rocha et al., 2020; Lu et al., 2021), the noise, smell and mess associated with roosts in residential areas (Aziz et al., 2017a), and for their consumption of fruit crops (Aziz et al., 2016); the latter has even induced mass culls of $\sim 50 \%$ of the endemic flying fox (Pteropus niger) population in Mauritius (Florens and Baider, 2019). Fruit bats also continue to be intensively harvested for consumption (Mildenstein et al., 2016), despite often dwindling populations, and despite zoonotic disease concerns.

The 201 species of pteropodids range from Africa, the eastern Mediterranean, Madagascar, Indian Ocean islands, across South and Southeast Asia, southern East Asia including Hong Kong and Taiwan, and throughout islands of the Pacific from the Ryukyu Archipelago, to coastal eastern Australia (including Christmas Island), Melanesia, Micronesia, and Polynesia excluding New Zealand and Hawai'i (Mickleburgh et al., 1992). Available data on the status of species suggest serious population declines for many, mainly due to habitat loss and overhunting, with $37 \%$ of assessed species being threatened (IUCN, 2020). Pteropodid declines will also result in plant declines, with ecosystem-wide repercussions.

Complex inter-relationships between Pteropodid bats and plants over millennia have resulted in "bat flowers" and "bat fruits" that are reliant on bats for pollination and/or seed dispersal (Marshall, 1983). Bat-plant interactions were first recorded in 1772 and compiled in the mid-1980s (Marshall, 1983, 1985), showing how pteropodids carry out vital ecological functions in diverse habitats, and are thus essential for the healthy functioning of ecosystems and economies (Marshall, 1985; Fujita and Tuttle, 1991; Mickleburgh et al., 1992; Richards, 1995; Lacher et al., 2019). On faunally depauperate islands, pteropodids play keystone roles as principal pollinators and seed dispersers (Elmqvist et al., 1992; Shanahan et al., 2001; Fleming and Racey, 2009; McConkey and Drake, 2015; Florens et al., 2017), while their high abundance on some continents ensures they are important providers of ecosystem services (Redford et al., 2013; Baker et al., 2018; van Toor et al., 2019; Laurindo et al., 2020). Many plants visited by pteropodids are utilised by humans, and thus have economic importance (Fujita and Tuttle, 1991; Kunz et al., 2011; Scanlon et al., 2014).

Although recent decades have seen a huge growth of papers on pteropodid diet and function, their role has likely been underestimated compared to the much more widely studied birds, primates, and large terrestrial mammals (Seltzer et al., 2013; Baker et al., 2018). Further, pteropodid species that can maintain plant populations in degraded areas regularly forage in isolated trees (Schmelitschek et al., 2009), and can be key to catalysing restoration in disturbed habitats (Sritongchuay et al., 2014; Oleksy et al., 2015). A comprehensive understanding of bat-plant interactions in the Old World is essential for defining their importance, and their benefits to humans which can help foster a much-needed and more favourable balance in public opinion, and direct research to important gaps in knowledge.

The goal of this paper is to synthesise the breadth of our latest knowledge on pteropodid diet and pteropodid-plant interactions, building from previous reviews and spanning more than three decades of research (1985-2020). We use this dataset to: (i) describe the confirmed and potential ecological roles that pteropodids perform, by evaluating studies on diet, foraging movement, pollination, and seed dispersal; (ii) summarise the main threats to these roles; and (iii) identify the most critical research gaps. This review thus covers the current state of knowledge regarding pteropodidplant interactions.

\section{METHODS}

In this review of more recent bat-plant interaction studies, we included interactions described in post-1985 reviews along with the many new studies since. We also included studies that investigated ecosystem services and disservices by pteropodids (Zhang et al., 2007).

With the exception of Pacific island nations and Papua New Guinea, data have been organised according to country and geopolitical regions (United Nations, 2020). We grouped together island nations of the regions Melanesia, Micronesia, and Polynesia as "The Pacific." For Africa, we treated insular and continental nations as separate regions.

Although this review covers all pteropodids across their range, for which the common term "fruit bats" is sometimes used, we use the terms "large pteropodid" and "large fruit bat" to refer only to species with either body weight $\geq 250 \mathrm{~g}$ or forearm length > $110 \mathrm{~mm}$ (following Pierson and Rainey, 1992; Kunz and Pierson, 1994), which includes the genera Acerodon, Aproteles, Desmalopex, Dobsonia, Eidolon, Hypsignathus, Pteralopex, Pteropus, and Styloctenium (Pierson and Rainey, 1992; Kunz and Pierson, 1994; genera list compiled by Mildenstein, 2002). We make this distinction as large fruit bats have distinctly different roles and ecosystem interactions compared to the small fruit bats (Richards, 1995), and also tend to be disproportionately targeted by hunters (Mildenstein et al., 2016).

We reviewed research articles worldwide, during the period 1985-2020, that dealt specifically with the following topics:

(1) diet (studies that investigated, identified and documented food plants consumed by pteropodids, including food choice experiments); 
(2) foraging movement (studies involving either long-distance tracking of movements, or feeding behaviour at food plants);

(3) pollination (studies involving exclusion experiments, effective pollen transfer, or effect of bat visitors on fruit set);

(4) seed dispersal (studies involving observations of dispersal distances, modelling of seed shadows, direct observations of bats carrying off fruit, ingestion of viable seeds, gut passage times, seed germination experiments, seedling/sapling recruitment, or seed predation observations);

(5) conflict between pteropodids and fruit growers, including owners of non-commercial backyard trees, which can be considered a form of ecosystem disservice (Zhang et al., 2007; Shackleton et al., 2016).

We collated a preliminary list of studies by performing a Boolean search with relevant wildcards on the ISI Web of Science database and Google Scholar (Supplementary Information 1).

We then used this database to conduct comprehensive analyses of research trends and information gaps. Other potentially relevant studies may be overlooked because they were unobtainable or inaccessible (e.g., behind paywalls, or in books, workshop proceedings, and local repositories inaccessible to the international community, or in a language other than English).

Scientific and common names of bat species follow the IUCN (2020). We made every effort to update all plant species names to the most current accepted taxonomic revisions rather than using obsolete names listed in the original studies; we used the online database The Plant List (2013) to verify the latest botanical nomenclature. However, we acknowledge that discrepancies still exist, particularly if further taxonomic revisions have occurred during the course of this review. Unresolved plant names, which could not be identified within current taxonomic databases (e.g., misassigned/misspelled names, obsolete names without contemporary equivalents, or synonyms with several matches), were indicated with question marks.

\section{Data Analysis}

Research trends from 1985 to 2020 were analysed and visualised based on regional and geopolitical boundaries, in order to understand research efforts across different countries and to inform future priorities and targets. The proportion of plant parts (e.g., fruits, flowers, and leaves) consumed by pteropodids was analysed at the levels of pteropodid genus and plant family. Data visualisation was conducted using the ggplot package in $\mathrm{R}$ 3.6.3 ( $\mathrm{R}$ Core Team, 2021) and Inkscape 1.0.1 (Inkscape Project, 2021).

The overall bat-plant interaction networks were visualised using the bipartite package in R 3.6.3 (R Core Team, 2021). For each network, interactions were summarised as a bipartite matrix, with each cell containing the number of interactions between each plant family and pteropodid genus.

Relationships among body size (in g), foraging distance, and fruit size were assessed using Spearman Rank correlations.

\section{RESULTS AND DISCUSSION}

We obtained 311 relevant studies on bat-plant interactions in the Old World published during 1985-2020: 204 from Web of Science, an additional 73 from Google Scholar, and 33 opportunistically. Of the 201 pteropodid bat species, 37\% ( $n=75$ ) have been studied, in 47 countries. Most of the studies documented diet (52\% of all studies; 67 pteropodid species), followed by foraging movement (49\%; 50 pteropodid species). Relatively few studies have directly investigated the roles played by pteropodids in seed dispersal (24\%; 41 pteropodid species), pollination (14\%; 19 pteropodid species), and conflict with fruit growers (12\%; 11 pteropodid species) (Figure 1). The database on all recorded pteropodid-plant interactions from 1985 to 2020 is in Supplementary Information 2. Detailed regional summaries of these studies are in Supplementary Information 3.

Pteropodids display unique feeding behaviours, and researchers have employed a variety of methods to study them. Pteropodid bats feed by squeezing out the juices of the plant part, which they swallow, and then spit out wads known as "ejecta" that contain the fibres and often seeds of the plant. Nectar is accessed by lapping with the bats' long tongues. Because only small seeds and juices are swallowed, morphological investigation of faecal samples on their own can generate biased diet accounts. To overcome this, some researchers use direct observations of feeding bats, collect dropped fruits and seeds, and/or record seedlings/saplings under feeding roosts and parent trees, to supplement information collected from faeces under day roosts.

Bat ejecta and partially eaten dropped fruits are distinctive, and provide reliable accounts of diet (Supplementary Information 4). Researchers have also used microscope analyses to identify the flower/nectar portion of the diet. More recently, molecular methods have been developed that can putatively detect all plant parts, although the limitation of this technique is that it does not distinguish the plant parts consumed, and therefore should not be used in isolation; these methods can only supplement morphological/microscopic methods but not replace them (Aziz et al., 2017b). As not all studies employed all methods equally, our results are necessarily biased by the different methodological approaches used, and variation in sampling effort (e.g., time period, seasonality, etc.).

\section{Pteropodid Diet}

Studies have recorded $\geq 1072$ food plant species from 493 genera and 148 families (Supplementary Information 2). Most plant taxa were recorded as being consumed for their fruit (71\% of species), followed by flowers (28.6\%) and leaves (8.9\%). For 16 pteropodid genera (including $80 \%$ of all pteropodid species) that had sample sizes exceeding 10 consumed plant species, nectarivory (defined as $>50 \%$ of diet species comprising floral resources following Fleming et al., 1987) was the least common diet type, found in three genera and four species (Eonycteris spelaea, Macroglossus minimus, M. sobrinus, Syconycteris australis) (Figure 2), all of which are small-bodied (16-59 g) (Supplementary Information 2). The large-bodied Pteropus ( $n=67$ species) are considered frugivores ( $>50 \%$ of diet 


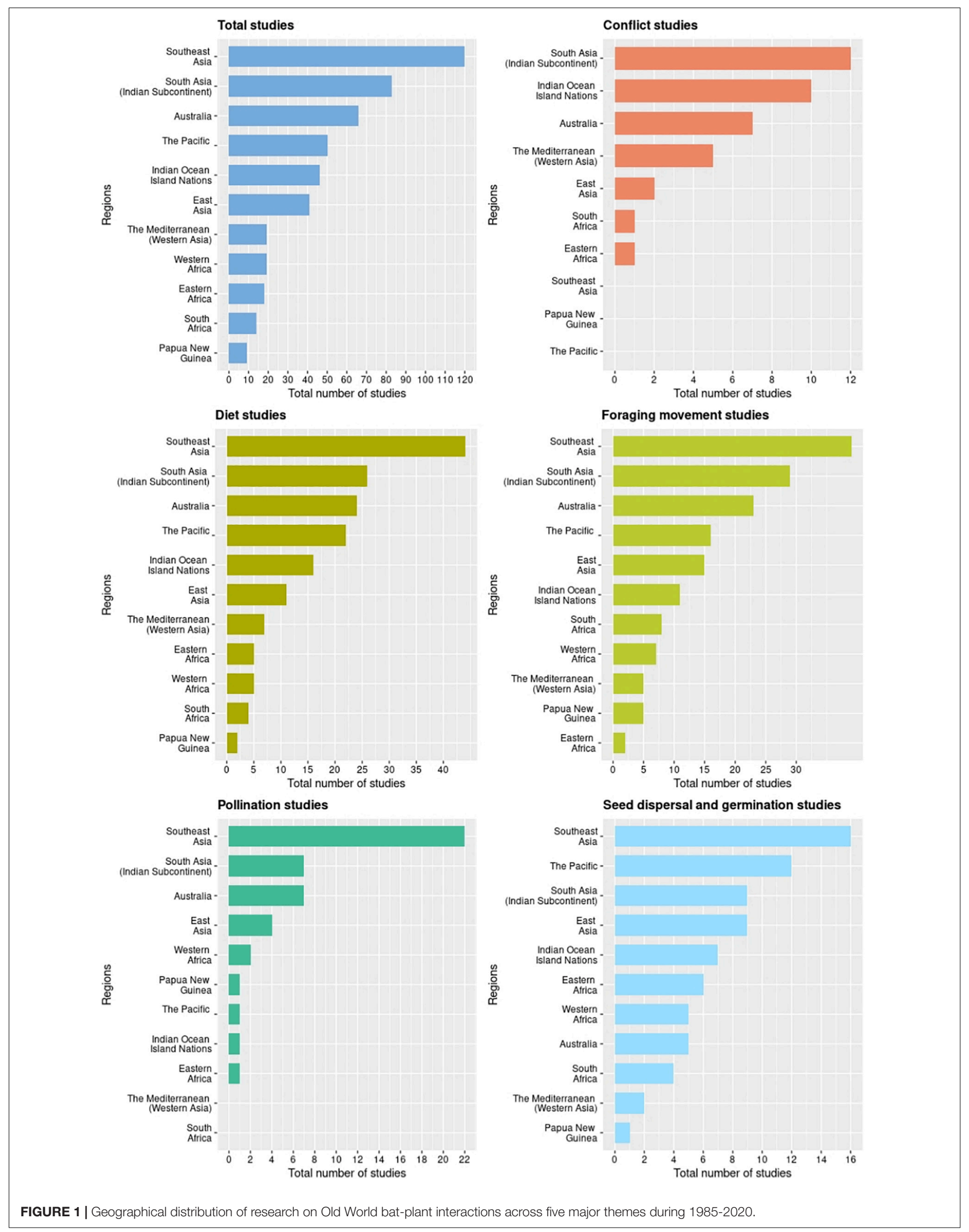




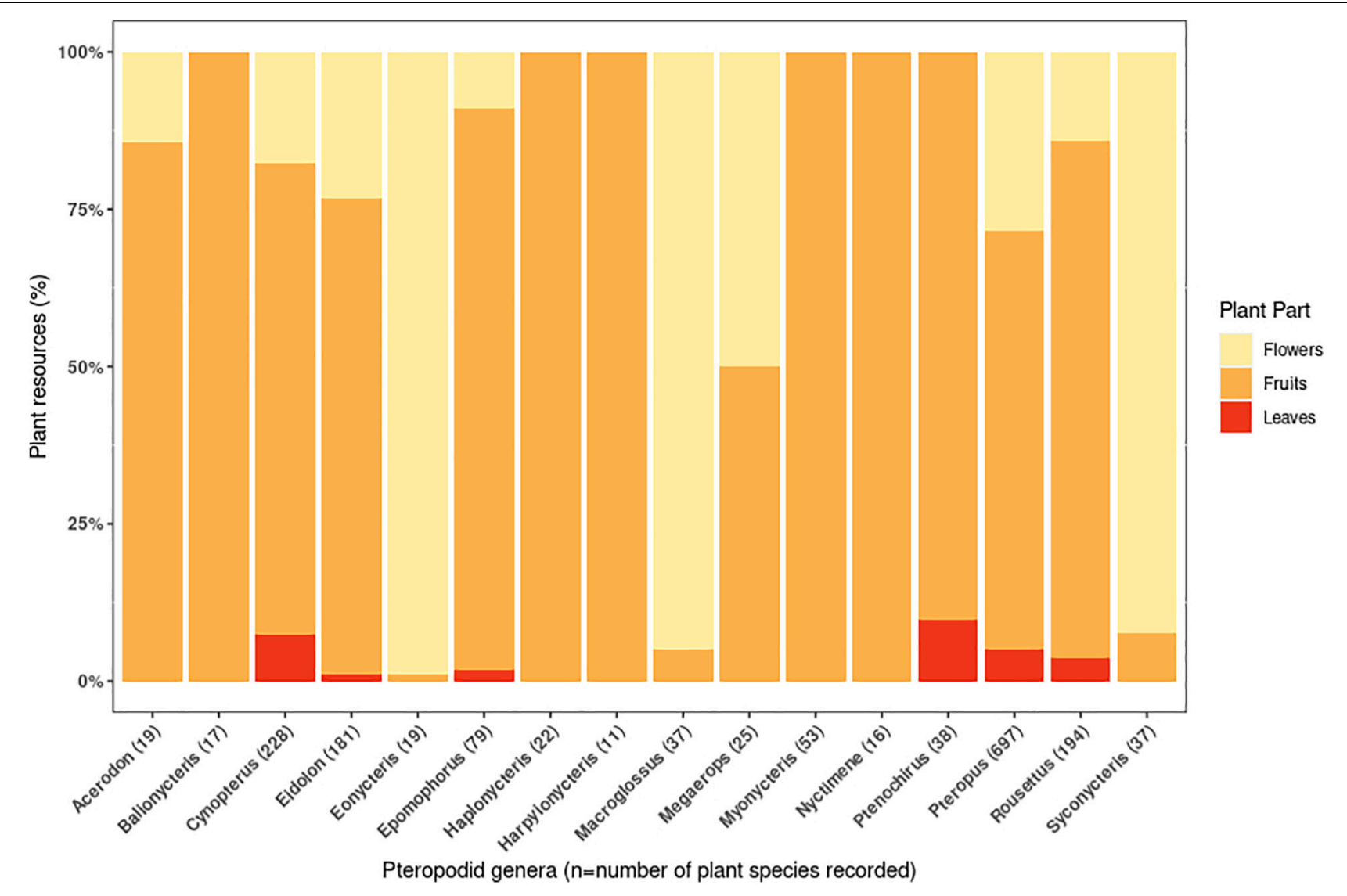

FIGURE 2 | Quantity of fruits, flowers and leaves recorded in the diets of pteropodid bats during 1985-2020. The quantity is represented by the proportion (percentage) of plant species consumed for each plant part, and is recorded for all studied species within 16 pteropodid genera. These genera fed on a minimum of 10 plant species recorded in the literature.

species were fruit) but had the most generalist diet, with $>25 \%$ of diet as flowers and leaves.

The remaining 12 pteropodid genera (24 species) were also frugivores, covering a wide range of body weights (14-1100 g). However, the majority of pteropodid studies are biased towards detecting fruit, because plant parts are often sampled under day or night roosts, and fruits leave more recognisable remains (i.e, seeds, skin, and pulp) than pollen/nectar and leaves. For this reason, leaf consumption is considered to be more widespread than reported; because of its relatively high protein content, the "juice" of the leaves is the only part swallowed by the bats (Kunz and Diaz, 1995; Nelson et al., 2000b). Also, some pteropodid genera such as Cynopterus, Megaerops, and Pteropus have been recognised as being frugi-nectarivorous (Stewart et al., 2014; Sritongchuay and Bumrungsri, 2016; Aziz et al., 2017b; Stewart and Dudash, 2018); in one 28-month study, the most frequently occurring food item in Pteropus rufus faeces was Agave sisalana pollen, and many faecal samples were pure Agave pollen (Long and Racey, 2007). Further studies on frugivorous bats, employing a more holistic combination of methods over longer time periods, may reveal more diverse diets than currently recognised.

At least seven other plant parts are consumed by pteropodids, although most of these have only been recorded for the more generalist Pteropus spp. (Table 1). Twigs are the most common of these other food items, followed by seeds. Seed-eating may often be misinterpreted as fruit consumption, as several plant species with dry fruits (lacking edible pulp) were recorded as fruit consumption in studies. Seed consumption occurred mostly in the leguminous plants from the family Fabaceae. Pteropodids also consumed shoots, sap, petioles, bark and the upper stem of plants.

The plant families Arecaceae (38 genera), Anacardiaceae (18 genera), and Musaceae (all species within the genus Musa) provide both floral and fruit resources to multiple bat genera (Figure 3). Floral resources were also commonly recorded from the families Fabaceae, Malvaceae, Myrtaceae, and Bignoniaceae, with both Fabaceae and Malvaceae providing multiple resources for the highest number of pteropodid genera. Moraceae and Annonaceae provided the most common fruit resources. Ficus was the most commonly consumed genus, with the syconia of 114 species consumed by pteropodids. Several studies have concluded that Ficus dominate the diet of pteropodids (e.g., Fujita and Tuttle, 1991; Shanahan et al., 2001; Stier and Mildenstein, 2005; Oleksy et al., 2015; Aziz et al., 2017b), possibly because of the availability and abundance across seasons (Eby, 1998), but determining the accuracy of this finding has been difficult given the sampling bias in field techniques. Small-seeded Ficus 
TABLE 1 | Plant parts that are a minor component in the diet of pteropodid bats.

\begin{tabular}{|c|c|c|c|}
\hline $\begin{array}{l}\text { Plant part } \\
\text { consumed }\end{array}$ & $\begin{array}{l}\text { \# plant } \\
\text { species }\end{array}$ & Plant families (Genera) & $\begin{array}{c}\text { Bat genera } \\
\text { consuming item }\end{array}$ \\
\hline Twigs & 10 & $\begin{array}{l}\text { Rubiaceae (Coffea) } \\
\text { Araliaceae (Schefflera) } \\
\text { Bromeliaceae (Ananas) } \\
\text { Elaeocarpaceae (Elaeocarpus) } \\
\text { Moraceae (Artocarpus, Ficus, } \\
\text { Morus) } \\
\text { Phyllanthaceae (Bischofia) } \\
\text { Theaceae (Schima) } \\
\text { Zingerbiaceae (Alpinia) }\end{array}$ & $\begin{array}{l}\text { Cynopterus } \\
\text { Pteropus }\end{array}$ \\
\hline Seeds & 7 & $\begin{array}{l}\text { Fabaceae (Acacia, Maniltoa, } \\
\text { Parkia, Pithecellobium) } \\
\text { Podocarpaceae (Podocarpus) } \\
\text { Arecaceae (Cycas) } \\
\text { Dipterocarpaceae (Shorea) }\end{array}$ & $\begin{array}{l}\text { Cynopterus } \\
\text { Pteropus }\end{array}$ \\
\hline Shoots & 3 & $\begin{array}{l}\text { Jubulaceae (Frullania) } \\
\text { Metzgeriaceae (Metzgeria) } \\
\text { Sematophyllaceae (Acroporium) }\end{array}$ & Pteropus \\
\hline Sap & 3 & $\begin{array}{l}\text { Streliziaceae (Ravenala) } \\
\text { Arecaceae (Cocos, Phoenix) }\end{array}$ & Pteropus \\
\hline Petioles & 1 & Fabaceae (Erythrina) & Pteropus \\
\hline Bark & 1 & Moraceae (Ficus) & Pteropus \\
\hline Upper stem & 1 & Poaceae (Saccharum) & Pteropus \\
\hline
\end{tabular}

species are more likely to be found in faeces and ejecta samples than large-seeded species, which are not swallowed. Molecular techniques (e.g., Sanger and Next-Generation Sequencing) have been more recently used to investigate pteropodid diet, and this has revealed more diverse diets than determined using traditional morphological or microscope analyses (Aziz et al., 2017b; Lim et al., 2018; Chan et al., 2020).

\section{Foraging Landscape of Pteropodids}

Of the 189 pteropodid species with habitat data recorded by the IUCN (2020), 11\% were listed as dependent on primary vegetation only. Secondary habitats and agricultural areas (plantations and/or gardens) were used by $56 \%$ and $50 \%$ of species, respectively. Fifteen species $(8 \%)$ are reported to use urban landscapes. Hence, the majority of pteropodid species (89\%) are using various stages of disturbed habitat, and could be contributing to restoration or plant gene flow via pollination and seed dispersal. They could also serve as essential mutualists that maintain plant populations and ecosystem services in humanmodified habitats (Sritongchuay et al., 2014; Oleksy et al., 2015; van Toor et al., 2019). However, this also means that the majority of pteropodids are utilising habitats that potentially bring them into conflict with humans (e.g., Aziz et al., 2016; Oleksy et al., 2018); illegal hunting is known to occur in $50 \%$ of foraging areas used by the commensal Pteropus lylei (Chaiyes et al., 2017).

Pteropodids use resources over a broad swathe of landscapes, with nightly foraging distances positively related to body size (Spearman Rank, $R=0.5539, n=25$ species). Movements ranged from an average of $0.1 \mathrm{~km}$ for the frugivorous Cynopterus spp. to $56 \mathrm{~km}$ for Eidolon helvum, also a frugivore ( $n=5$ studies, Table 2 and Supplementary Information 5). Within this range of foraging distances travelled, the nectarivorous species generally moved shorter distances, averaging 0.25 to $5.21 \mathrm{~km}$. Maximum distance moved in a night was also positively related to body size ( $R=0.5599, n=22$ studies), with the longest maximum distances recorded for Eidolon and Pteropus $(88 \mathrm{~km})$. Within the landscapes where they forage, pteropodids use cognitive map-based navigation to forage amongst resources (Rousettus aegyptiacus, Harten et al., 2020; Toledo et al., 2020); R. aegyptiacus flew distances of up to $25 \mathrm{~km}$ from day roosts using a fast and straight flight track, showing loyalty to visited fruiting trees and the flight track (Tsoar, 2011). The rest of the night's foraging was spent within the vicinity of the first flight until returning to the roost before sunrise. These flight patterns have consequences for the spatial pattern of defecated seeds, with potentially very different dispersal distances achieved for seeds swallowed earlier in the night compared to those consumed later - but this aspect is currently still unstudied.

At least seven species migrate seasonally to track food resources (Eidolon helvum, Myonycteris torquata, Nanonycteris veldkampii, Pteropus alecto, P. poliocephalus, P. scapulatus, and P. vampyrus; Thomas, 1982; Richards, 1995; Richter and Cumming, 2008; Epstein et al., 2009; Moussy et al., 2013; Fleming, 2019), potentially resulting in long-distance pollen and seed movement (see below). During migration, distances of up to $370 \mathrm{~km}$ were recorded in a single night for E. helvum, with individuals travelling more than $2,500 \mathrm{~km}$ in total (Richter and Cumming, 2008). The fastest travel was recorded for P. vampyrus, moving $130 \mathrm{~km}$ in $2 \mathrm{~h}$ during migration (Epstein et al., 2009). Indirect evidence for seasonal movements related to food availability has been recorded for two of eight species studied in Malaysian forests (Cynopterus horsfieldii, Megaerops ecaudatus) (Hodgkison et al., 2004). Australian Pteropus species are highly nomadic with little uniformity among individuals (Welbergen et al., 2020), moving annually around roosts (and presumably feeding resources) across broad swathes of landscapes, with distances ranging from 1400 to $6000 \mathrm{~km}$. Even for the species that do not migrate, single long-distance flights have been recorded; e.g., the $37 \mathrm{~g}$ Cynopterus sphinx and C. horsfieldii flew $10 \mathrm{~km}$ over open water to colonise Krakatau Island (Whittaker and Jones, 1994), and many island-dwelling populations move around naturally fragmented landscapes on a nightly basis (McConkey and Drake, 2007; Oleksy et al., 2019).

\section{Pteropodids as Pollinators}

Sixteen pteropodid species from eight genera have been proven to function as pollinators (Table 3), based on robust scientific evidence obtained from in-depth investigations beyond mere documentation of diet, flower visitation or pollen load. Of these, the genus Pteropus appears to include a disproportionately high number of pollinating species within the guild ( $n=7 ; 44 \%$ of all known pteropodid pollinators), related to seven different plant species, though this likely reflects the high species diversity within this pteropodid genus. The nectarivorous species Eonycteris spelaea alone has been proven to be a particularly important pollinator for seven different plant species, and the genus Macroglossus appears to be specifically important for wild bananas (Musa spp.) and mangrove ecosystems (Momose et al., 1998; Watzke, 2006; 
A

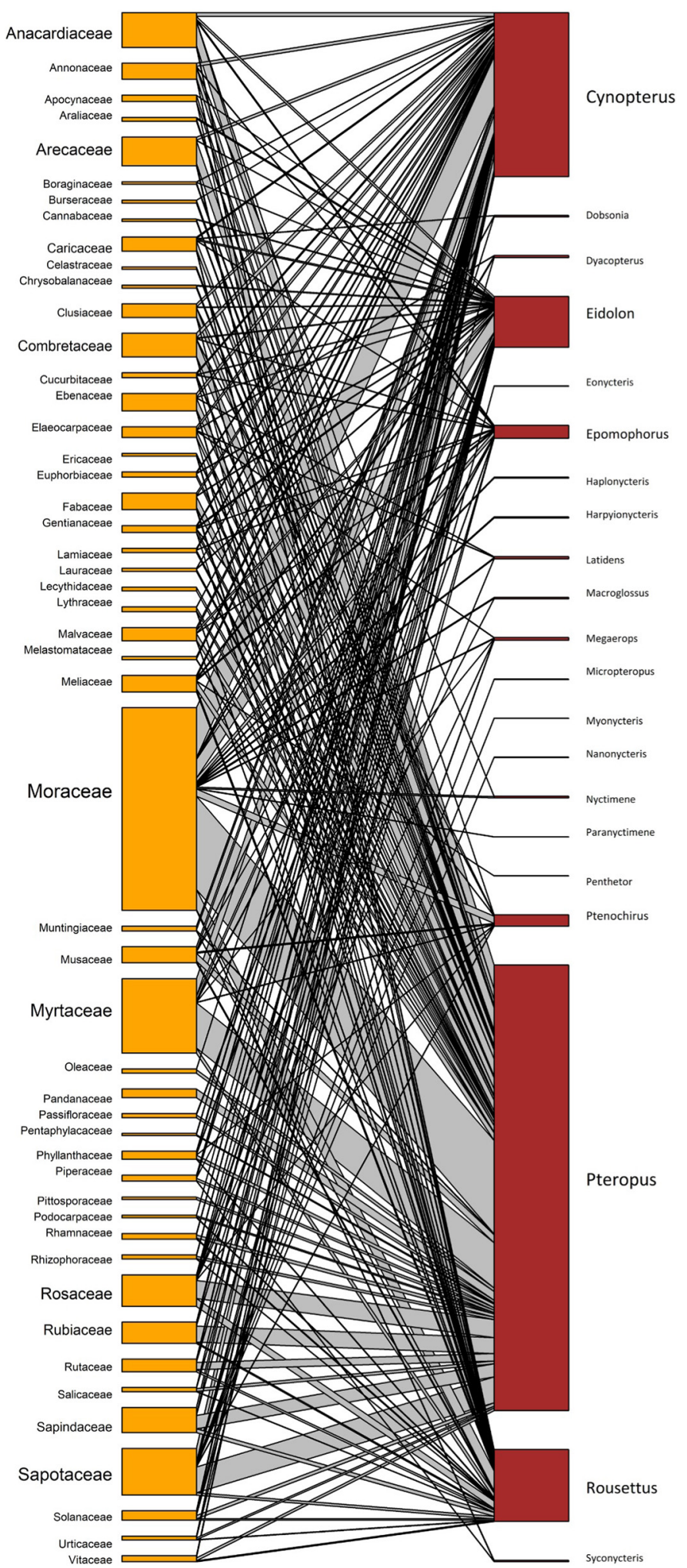

B Flowers

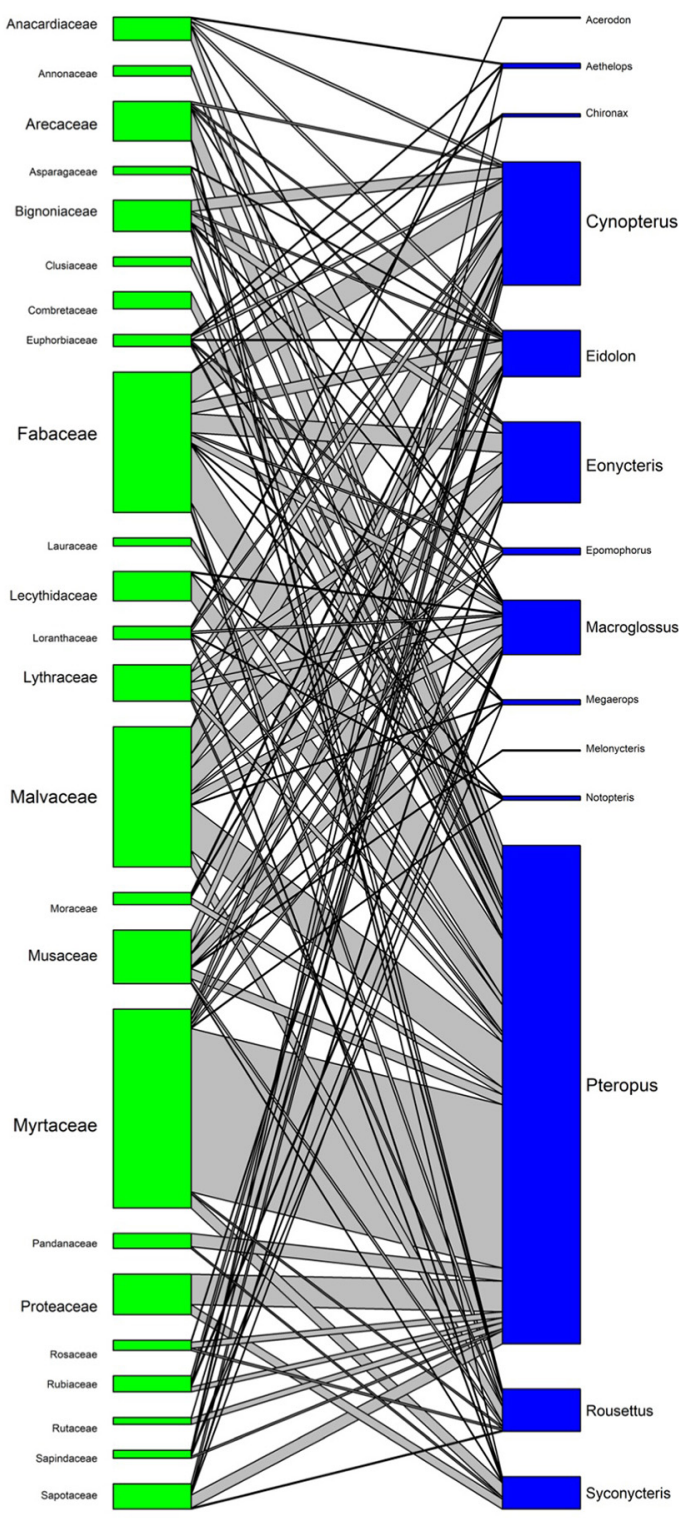

FIGURE 3 | Network graphs showing interactions between pteropodid bats (right) and the plant taxa (left; (A) flowers and (B) fruit) they interact with. Graphs are based on the number of species within each family consumed by pteropodid genera for five or more interactions recorded. 
TABLE 2 | Summary of movement studies on pteropodid genera (1985-2020).

\begin{tabular}{|c|c|c|c|c|c|c|}
\hline \multirow[t]{2}{*}{ Genera } & \multirow[t]{2}{*}{ Diet } & \multirow[t]{2}{*}{ Body weight (g) } & \multicolumn{2}{|c|}{ Distance (km) } & \multirow[t]{2}{*}{ No. of studies } & \multirow[t]{2}{*}{ Location of study } \\
\hline & & & Mean & Max & & \\
\hline Acerodon & Fruit & $470-1100$ & 21.0 & 87.0 & 1 & Philippines \\
\hline Balionycteris & Fruit & 14 & $<1$ & & 1 & Malaysia \\
\hline Cynopterus & Fruit & $26-58$ & 1.7 & 6.0 & 6 & China, India, Malaysia \\
\hline Dobsonia & Fruit & 87 & 0.6 & 1.2 & 1 & Papua New Guinea \\
\hline Eidolon & Fruit & $250-300$ & 56.1 & 88.0 & 5 & Burkina Faso, Ghana, Zambia \\
\hline Eonycteris & Flower & 59 & 5.21 & 17.9 & 2 & Thailand \\
\hline Epomophorus & Fruit & $80-110$ & 1.44 & 13.9 & 3 & South Africa \\
\hline Macroglossus & Flower & $16-22$ & 1 & & 1 & Papua New Guinea \\
\hline Melonycteris & Flower & 48 & 0.25 & 0.4 & 1 & Papua New Guinea \\
\hline Nyctimene & Fruit & $30-49$ & 0.5 & 1.1 & 1 & Australia \\
\hline Ptenochirus & Fruit & $63-80$ & 0.47 & 0.48 & 1 & Philippines \\
\hline Pteropus & Fruit & $440-820$ & 9.7 & 87.5 & 16 & $\begin{array}{c}\text { American Samoa, Australia, } \\
\text { Cambodia, India, Japan, India, } \\
\text { Madagascar, Pakistan, Palau, } \\
\text { Thailand }\end{array}$ \\
\hline Rousettus & Fruit & $45-125$ & 7.2 & 31.6 & 8 & $\begin{array}{c}\text { China, Cyprus, Israel, } \\
\text { Madagascar, South Africa, }\end{array}$ \\
\hline Syconycteris & Flower & 18 & 1.1 & 6.8 & 2 & Australia \\
\hline
\end{tabular}

The main diet of the bat is indicated, according to whether they are nectarivores or frugivores. Mean and maximum movements in a single night are recorded in kilometres. Sources of variation in movement patterns are indicated where these have been described. Data came from 56 studies, but were focused mainly on Pteropus ( $n=23$ ). Supplementary Information 5 has full details on foraging distances.

Nor Zalipah et al., 2016; Stewart and Dudash, 2016, 2018; Nor Zalipah and Ahmad Fadhli, 2017; Nuevo Diego, 2018; Nuevo Diego et al., 2019), underscoring the obligate pollinator roles of the latter two genera. However, the apparently disproportionate pollinating role of Eonycteris spelaea compared to other species may also be a reflection of research effort, as this species is commonly found in human-dominated landscapes across most Southeast Asian countries (Francis et al., 2008), and therefore easily studied in comparison to other species. Further research would be helpful in elucidating the pollinating roles of the comparatively more threatened and rare Pteropus, Acerodon, and Desmalopex, critical facultative pollinators despite being classified as frugivores. Some of the larger Pteropus species have been implicated in the destruction of flowers (Soepadmo and Eow, 1977; Elmqvist et al., 1992; Nathan et al., 2009; Stephenraj et al., 2010), but this has either been incorrectly assumed (Gumal, 2001; Aziz et al., 2017c), or their positive impacts as pollinators have overridden negative effects of their feeding behaviour (Elmqvist et al., 1992; Stephenraj et al., 2010; Toyama et al., 2012). Pteropus scapulatus exhibits behaviour and a tongue structure that are more reminiscent of nectar-feeding bats (Birt, 2004), indicating a need to investigate the diet of all pteropodid species in more detail to understand and compare their functional roles. Documented food plants and foraging behaviour of this bat taxon provide clues that should direct future research.

Twenty-one different plant species from eight plant families are now known to be pollinated by pteropodids Table 3; families Fabaceae, Lythraceae, Malvaceae, Musaceae and Myrtaceae appear to have particularly important coevolutionary relationships with bats, containing multiple species that are known to be almost entirely dependent on pteropodids for effective long-distance pollen transfer (Crome and Irvine, 1986; Elmqvist et al., 1992; Law and Lean, 1999; Birt, 2004; Boulter et al., 2005; Bumrungsri et al., 2008, 2009; Bacles et al., 2009; Acharya et al., 2015; Groffen et al., 2016; Aziz et al., 2017c; Sheherazade et al., 2019; Sritongchuay et al., 2019). These plant taxa that have close associations with bats display characteristics of chiropterophily: flowers are light-coloured, large, presented on the periphery of the canopy and produce more nectar and pollen at night (Marshall, 1983). In a highly specialised case, the flowers of Mucuna macrocarpa in Japan open explosively when triggered by foraging Pteropus dasymallus, which allows pollination to occur (Toyama et al., 2012). However, just as bats can be effective dispersers of fruits that are not adapted for bat dispersal, we need improved documentation of their pollination importance for plants that are less specialised for bats.

At a community level, nectarivorous bats have been found to have higher network strength, abundance (Sritongchuay and Bumrungsri, 2016) and generalised degree (number of interactions per species divided by the number of possible interacting partners; Sritongchuay et al., 2019) than other pteropodids. However, the temporal and spatial differences that these bats show in their feeding patterns, when compared to large bats such as Pteropus (Aziz et al., 2017c), could suggest complementary roles in pollination. Bats are more effective pollinators than other animals for most of the documented plant species (Ratto et al., 2018; Sheherazade et al., 2019), carrying more pollen and moving across larger landscape areas compared to nectar-feeding birds (Law and Lean, 1999) or native bees (Wayo et al., 2018; Sheherazade et al., 2019). However, this finding also 
TABLE 3 | Confirmed pteropodid pollinators and their associated bat-pollinated plant species.

\begin{tabular}{|c|c|c|c|}
\hline Bat Pollinator & Plant Family & Plant Species & Source/Study \\
\hline Acerodon celebensis & Malvaceae & Durio zibethinus & Sheherazade et al., 2019 \\
\hline \multirow[t]{2}{*}{ Cynopterus sphinx } & Fabaceae & Mucuna championii & Kobayashi et al., 2020 \\
\hline & Sapotaceae & Madhuca longifolia var. latifolia & Nathan et al., 2009; Stephenraj et al., 2010 \\
\hline Eidolon dupreanum & Malvaceae & Adansonia suarezensis & Baum, 1995 \\
\hline \multirow[t]{7}{*}{ Eonycteris spelaea } & Bignoniaceae & Oroxylum indicum & Sritongchuay et al., 2008 \\
\hline & Fabaceae & Parkia speciosa & Bumrungsri et al., 2008 \\
\hline & & Parkia timoriana & Bumrungsri et al., 2008 \\
\hline & Lythraceae & Sonneratia alba & Nor Zalipah et al., 2016 \\
\hline & & Sonneratia caseolaris & Nor Zalipah et al., 2016 \\
\hline & & Sonneratia griffithii & Nuevo Diego, 2018 \\
\hline & Malvaceae & Durio zibethinus & $\begin{array}{l}\text { Bumrungsri et al., 2009; Aziz et al., 2017b; } \\
\text { Chaiyarat et al., 2019; Sheherazade et al., } 2019\end{array}$ \\
\hline \multirow[t]{3}{*}{ Macroglossus minimus } & Lythraceae & Sonneratia caseolaris & Watzke, 2006 \\
\hline & & Sonneratia griffithii & Nuevo Diego, 2018 \\
\hline & & Sonneratia ovata & Nuevo Diego et al., 2019 \\
\hline \multirow[t]{2}{*}{ Macroglossus sobrinus } & Musaceae & Musa acuminata halabanensis & Itino et al., 1991 \\
\hline & & Musa itinerans & Liu et al., 2002 \\
\hline Pteropus alecto & Malvaceae & Durio zibethinus & Sheherazade et al., 2019 \\
\hline Pteropus conspicillatus & Myrtaceae & Syzygium sayeri & Boulter et al., 2005 \\
\hline Pteropus dasymallus & Fabaceae & Mucuna macrocarpa & Toyama et al., 2012 \\
\hline \multirow[t]{3}{*}{ Pteropus giganteus } & Bixaceae & Cochlospermum religiosum & Erancheri et al., 2013 \\
\hline & Malvaceae & Ceiba pentandra & Nathan et al., 2005 \\
\hline & Sapotaceae & Madhuca longifolia var. latifolia & Nathan et al., 2009 \\
\hline Pteropus hypomelanus & Malvaceae & Durio zibethinus & Aziz et al., 2017c \\
\hline Pteropus poliocephalus & Myrtaceae & Corymbia citriodora & Bacles et al., 2009 \\
\hline Pteropus tonganus & Malvaceae & Ceiba pentandra & Elmqvist et al., 1992 \\
\hline Rousettus leschenaultii & Malvaceae & Ceiba pentandra & Nathan et al., 2005 \\
\hline Pteropodidae (species unknown) & Fabaceae & Parkia biglobosa & Lassen et al., 2012 \\
\hline $\begin{array}{l}\text { Pteropodidae spp. (either } \\
\text { Macroglossus lagochilus or } \\
\text { Syconycteris australis, or both; } \\
\text { indistinguishable in the field) }\end{array}$ & Myrtaceae & Syzygium cormiflorum & Crome and Irvine, 1986 \\
\hline $\begin{array}{l}\text { Pteropodidae spp. (Macroglossus } \\
\text { minimus \& Syconycteris australis } \\
\text { grouped together without } \\
\text { species-specific diet) }\end{array}$ & Myrtaceae & Syzygium sayeri & Boulter et al., 2005 \\
\hline Pteropodidae (species unknown) & Malvaceae & Adansonia digitata & Djossa et al., 2015 \\
\hline
\end{tabular}

reflects the choice of plants studied, which have been primarily crop or timber plants important to humans that were already suspected to be bat-pollinated. To understand the importance of bat pollination at the community level, we require more studies in wild ecosystems, but the cost, effort and time required to confirm pollination in these environments is likely to be challenging.

\section{Pteropodids as Seed Dispersers}

Seed dispersal studies, including seed germination experiments, have been conducted on 41 pteropodid species from 15 genera, but only 29 pteropodid species from 9 genera have been recorded actively dispersing seeds, with documented dispersal for fruits from 311 plant species from 184 genera and 75 families. The genera with the most bat-dispersed species were Ficus (60 species), Syzygium (14 species), and Diospyros (8 species). Bats processed seeds gently in most cases (see below), and therefore most of the 687 species listed as fruit resources in our database (Supplementary Information 2) are potentially dispersed by bats. Six methods have been used to document seed dispersal by different pteropodid species (Table 4). Direct observations at the parent tree or of fruit being carried away have been observed for most species, followed by investigations of ejecta and faeces under day roosts.

\section{Fruit Selection}

The primary cue pteropodids use for finding fruit and determining ripeness is odour Kshitish (Acharya et al., 1998; Luft et al., 2003; Hodgkison et al., 2007, 2013; Raghuram et al., 2009; Shafie et al., 2014), and a strong odour is among the plant traits considered indicative of bat attraction and the bat-fruit syndrome (Bollen et al., 2004; Hodgkison et al., 2013). However, pteropodids also rely, to a significant extent, on vision and have enlarged eyes and a visual cortex (Speakman, 2001). Researchers 
have suggested "light-coloured" fruit (and probably flowers) are an adaption for bats to find food in dark conditions (Richards, 1990), although bats consume fruit exhibiting a diversity of colours (Hodgkison et al., 2003), and at least some pteropodids are sensitive to the ultraviolet spectrum ( $\mathrm{Li}$ et al., 2018). Other characteristics of bat-preferred fruits include fruits with high quantities of water and sugar, and low quantities of fats and proteins (Korine et al., 1998; Bollen et al., 2004; Nelson et al., 2005) and an unusual syndrome of dry fruits with a high protein content found in Mediterranean habitats (Korine et al., 1998). Fruit displays, in which the fruits are held away from the foliage and therefore more accessible to bats, are also commonly reported in bat-consumed fruits. These include fruits produced from the trunk (cauliflory), fruits available from leafless main branches (ramicarpy), or fruits on the end of long downwardpointing peduncles (flagelliflory) (Richards, 1995; Hodgkison et al., 2003; Bollen et al., 2004).

Across the studies, information was only available on fruit colour (collected for $n=141$ plant species) and not fruit odour, chemical composition or display. Bats dispersed seeds from fruits representing a diverse range of colours; here we categorised most species as red (31 species), green (29 species), or yellow (23 species). Fewer fruits were purple (15 species), brown (12 species), orange (11 species), black (10 species), or white (7 species), with just a few species having blue ( 2 species) or pink (1 species) fruits. While this colour diversity is predominantly light coloured (yellow, orange, or white $=41$ species) or with no distinguishing colour against the background (dull: green or brown $n=41$ species), collectively, the bats show use of a broad range of fruit colours (59 species that are neither dull nor light).

Some pteropodid species are regular visitors to orchards and/or gardens, where they come into conflict with farmers by consuming fruit crops (Aziz et al., 2016). Foraging Pteropus tonganus in Fiji was four times more abundant in farmland than in forests, and territorial disputes over food were only documented in farmland (Luskin, 2010). This suggests a potential preference for cultivated landscapes, either because of resource distribution, resource abundance, and/or the nutritional content of the plant resources, which could disrupt natural seed dispersal processes (McConkey and Drake, 2006). However, even though bats can consume large quantities of cultivated fruits (Oleksy et al., 2018), some studies have found that pteropodids prefer to forage on native species rather than on introduced fruits (Korine et al., 1999; Nelson et al., 2000a; Mildenstein et al., 2005; Andrianaivoarivelo et al., 2012).

\section{Fruit Processing}

Pteropodids feed by mainly swallowing fruit juices, spitting out fruit fibres and seeds as ejecta. Seeds are dispersed in ejecta, by swallowing and defecating, and by physically carrying the entire fruit; for all dispersal modes researchers report "gentle" seed treatment where seeds are dispersed undamaged. The capacity to swallow seeds is limited to the diameter of the oesophageal lumen, which can extend to 4-5 $\mathrm{mm}$ in the larger Australian Pteropus (Richards, 1995). Hence, only small seeds ( $\leq 6 \mathrm{~mm}$ width) are dispersed through swallowing and defecation (Shilton et al., 1999; Shanahan et al., 2001; Oleksy et al., 2017). The largest seeds dispersed by defecation were $6 \mathrm{~mm}$ wide (Pteropus rufus in Madagascar; Bollen et al., 2004), and large fruit bats could disperse slightly larger seeds than small fruit bats in this way (Spearman Rank test significant at $10 \%$ level; $R=0.3934$, $n=22$ bat species); however, the fruit size of defecated seeds was unrelated to bat size ( $R=0.5003, n=19$ bat species). Seeds dispersed by ejecta were inconsistently reported, so we did not test for a relationship with body size. Maximum widths of $12 \mathrm{~mm}$ were noted in ejecta, and often seeds dispersed by defecation were also dispersed in ejecta.

Seeds that are too large to be swallowed are dispersed when bats carry fruits in their mouth away from the parent plant. The largest seed dispersed by pteropodids was for Mangifera indica which can reach widths of $71 \mathrm{~mm}$. Mangifera was only consumed by large bats ( $\geq 250 \mathrm{~g}$ in body weight), indicative of the positive relationship between seed width and pteropodid body size ( $R=0.6994, n=14$ bat species), and fruit width and pteropodid body size ( $R=0.8299, n=12$ bat species). More important than the width of the fruit is its weight, and pteropodids can carry heavy fruits relative to their body weight. This has rarely been described, but the weight of carried fruits has ranged from 0.5 to $1.6 \mathrm{x}$ the body weight of the bat (Nakamoto et al., 2015; Mahandran et al., 2018). Therefore, pteropodids of more than $1 \mathrm{~kg}$ could potentially have the capacity to disperse fruits of more than $1.5 \mathrm{~kg}$ - though this requires further investigation.

The ability of pteropodids to carry heavy fruits indicates that body mass alone is a poor surrogate of these bats' dispersal abilities, as pteropodids are potential dispersers of fruits consumed by much larger animals - even elephants and rhinoceroses, which disperse mango seeds via defecation (Sridhara et al., 2016). Pteropodids can also consume large quantities of fruit relative to their own body mass; e.g., Rousettus aegyptiacus consumes fruit up to a maximum of $150 \%$ of its body mass (Izhaki et al., 1995). The high density at which some populations of large pteropodids can occur (Richter and Cumming, 2005; Tait et al., 2014) also implies high rates of consumption at the community level. This has rarely been quantified, but a single colony of Eidolon helvum, estimated at 152,000 individuals, was predicted to provide 338,000 dispersal events in a single night (van Toor et al., 2019). Even during the seasonal reduction in colony size, the authors estimated these bats moved 5,500 seeds in a night.

Population abundance is a key factor driving the seed dispersal importance of Neotropical bats (Laurindo et al., 2020), and is likely to be of similar importance for pteropodids. The importance of abundance per se has not been investigated in pteropodids, but sufficient population density to induce territorial disputes is essential for effective seed dispersal of largeseeded fruit by Pteropus species (Richards, 1995; McConkey and Drake, 2006; Mahandran et al., 2018). Pteropus preferentially feed on and defend small territories within fruiting trees. Seed dispersal occurs when newcomers attempting to access the tree cannot forage, because the tree is full of feeding territories already claimed by earlier arrivals - the "raiders versus residents" phenomenon (Richards, 1990). The new arrivals snatch a fruit and fly elsewhere to consume it, hence dispersing the seed from the parent tree. This behaviour has not been reported 
for other genera apart from Eidolon (Racey, pers. obs.), but small pteropodids frequently remove fruit from a parent tree for consumption at regularly used feeding roosts (Utzurrum, 1995; Deshpande and Kelkar, 2015). This feeding behaviour results in more consistent seed dispersal than that by the large 'resident feeder' pteropodids who may usually consume fruit more often at the parent plant, and are thus only effective at dispersing swallowed seeds. Eleven of these small pteropodid species with available seed dispersal information have been noted to use feeding roosts and/or have been observed carrying fruit away from the parent tree (Table 4).

\section{Seed Consumption}

While researchers report consistently gentle seed processing by pteropodids, some seed-eating has been recorded in at least three Pteropus species (involving Cycas spp., Cox et al., 2003; Podocarpus pallidus, Maniltoa grandiflora, McConkey and Drake, 2015; Shorea sp. and an unknown species, Ong, 2020). "Fruit" consumption recorded for plants that have no fleshy portion are potentially also examples of seed consumption. For large seeds, such as Cycas spp. and Maniltoa grandiflora, consumption does not necessarily prevent effective seed dispersal, since seeds are not entirely consumed and could still germinate (McConkey and Drake, 2015). Seed-eating bats have also been recorded in the Neotropics, where Chiroderma spp. have cranio-dental morphology that promotes consumption of fig seeds (Nogueira and Peracchi, 2003; Nogueira et al., 2005); Centurio senex has also been recorded eating seeds with soft endocarps (Villalobos-Chaves et al., 2016). It is possible that seed-eating is more prevalent than currently appreciated in pteropodids, as an alternative strategy to folivory and insectivory, to obtain sufficient protein (Courts, 1998; Clulow and Blundell, 2011). Given the lack of apparent morphological adaptations to consume hard items, seed-eating by pteropodids would be expected to be limited to softer seeds; however, Latidens salimalii possibly consumes the softer content of nuts by biting through an extremely hard, thick coat (Agoramoorthy and Hsu, 2005).

\section{Dispersal Distances}

Some pteropodid species have the capacity to disperse seeds farther than has been recorded for any other animal (Figure 4). The maximum dispersal distances recorded for small bats $(<250 \mathrm{~g}$ ) were $30 \mathrm{~km}$ for defecated seeds ( $n=6$ studies) with fattailed kernels (Tsoar, 2011), while larger bats ( $\geq 250 \mathrm{~g}$ ) defecated seeds over distances up to $24 \mathrm{~km}$ (non-migratory) and $88 \mathrm{~km}$ (migratory) ( $n=8$ studies) (Supplementary Information 6). Most seeds pass through pteropodid guts in 30-116 min, but some seeds are retained for up to $24 \mathrm{~h}$ (Shilton et al., 1999; AbediLartey, 2016; Oleksy et al., 2017). If the longer gut retention

TABLE 4 | Seed dispersal study methods according to pteropodid species.

\begin{tabular}{|c|c|c|c|c|c|c|}
\hline Bat species & $\begin{array}{l}\text { Observed in } \\
\text { parent tree }\end{array}$ & $\begin{array}{l}\text { Observed } \\
\text { carrying fruit } \\
\text { away }\end{array}$ & $\begin{array}{c}\text { Ejecta/faecal } \\
\text { samples below } \\
\text { feeding roost }\end{array}$ & $\begin{array}{l}\text { Seed traps/ejecta/faecal } \\
\text { samples below day roost }\end{array}$ & $\begin{array}{l}\text { Ejecta beneath } \\
\text { parent tree }\end{array}$ & $\begin{array}{c}\text { Ejecta/faecal } \\
\text { samples along } \\
\text { transects }\end{array}$ \\
\hline Cynopterus brachyotis & $x$ & $x$ & $x$ & $x$ & & $x$ \\
\hline Cynopterus horsfieldii & $x$ & $x$ & & $x$ & & \\
\hline Cynopterus minutus & $x$ & $x$ & & & & \\
\hline Cynopterus sphinx & $x$ & $x$ & $x$ & $x$ & & \\
\hline Cynopterus titthaecheilus & $x$ & $x$ & & & & \\
\hline Eidolon helvum & & $x$ & & $x$ & & \\
\hline Epomophorus crypturus & $x$ & $x$ & & & & \\
\hline Epomophorus wahlbergi & $x$ & $x$ & & & & \\
\hline Macroglossus minimus & & & & & & $x$ \\
\hline Macroglossus sobrinus & $x$ & $x$ & & & & \\
\hline Nyctimene rabori & & & & $x$ & & \\
\hline Ptenochirus jagori & & & & $x$ & & $x$ \\
\hline Ptenochirus minor & & & & & & $x$ \\
\hline Pteropus conspicillatus & $x$ & $x$ & & $x$ & & \\
\hline Pteropus dasymallus & & $x$ & $x$ & & $x$ & $x$ \\
\hline Pteropus giganteus & $x$ & $x$ & & $x$ & & \\
\hline Pteropus mariannus & & & & & & $x$ \\
\hline Pteropus niger & & & & & & $x$ \\
\hline Pteropus poliocephalus & & & & & $x$ & \\
\hline Pteropus rufus & $x$ & & $x$ & $x$ & & \\
\hline Pteropus samoensis & & $x$ & & & & \\
\hline Pteropus tonganus & $x$ & & & $x$ & $x$ & $x$ \\
\hline \multicolumn{7}{|l|}{ Rousettus aegypticus } \\
\hline Rousettus amplexicaudatus & & $x$ & & & & \\
\hline Rousettus leschenaultii & & $x$ & & $x$ & & \\
\hline Rousettus madagascariensis & $x$ & $x$ & & & & \\
\hline
\end{tabular}




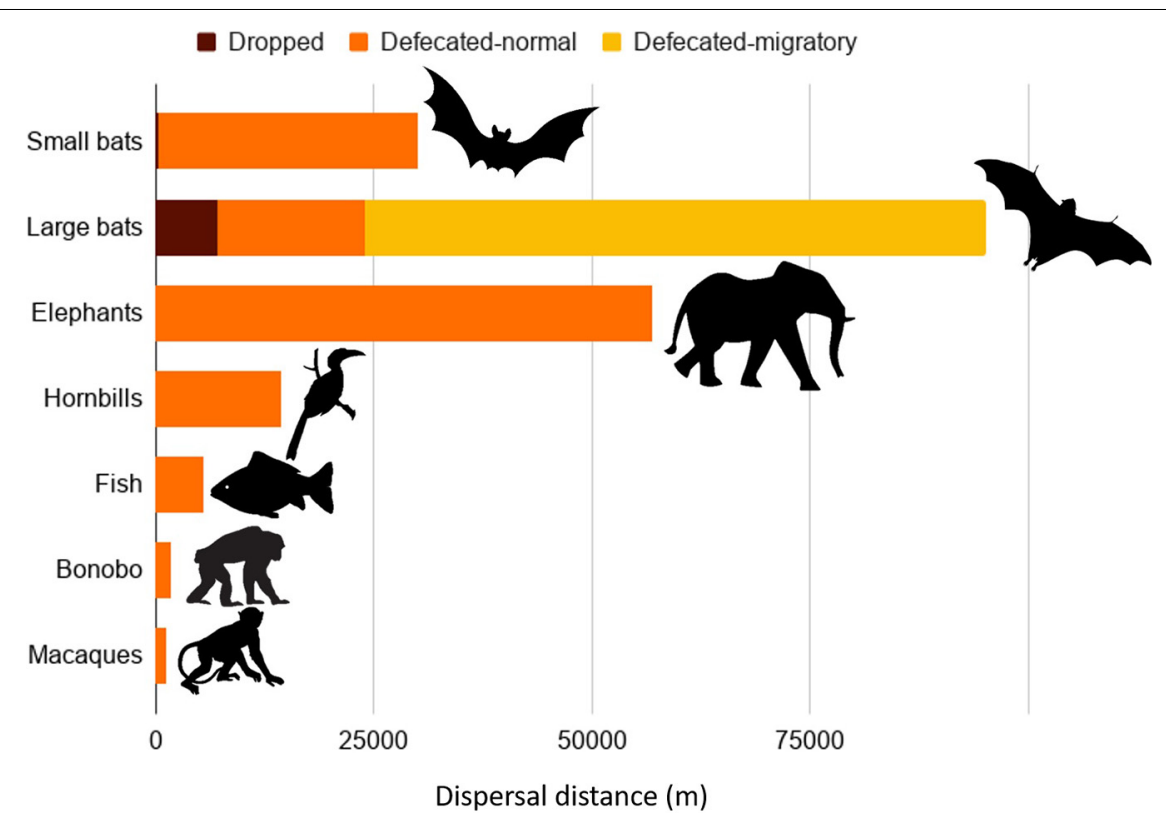

FIGURE 4 | Maximum seed dispersal distances for small ( $<250 \mathrm{~g}$ ) and large ( $\geq 250 \mathrm{~g}$ ) pteropodid bats and the comparison with other taxa confirmed to perform long-distance seed dispersal. References for the comparisons are given in the text. Dispersal distances for bats are given for seeds defecated without swallowing (dropped or spat), and defecated seeds during migratory and non-migratory periods.

times are used to estimate dispersal distances, bats can potentially disperse seeds up to $300 \mathrm{~km}$ from the parent tree (Shilton et al., 1999), at least for migratory species that traverse such long distances. These dispersal distances are within (or farther than) the maximum range reported for the longest seed dispersers recorded: elephants (6-57 km; Campos-Arceiz and Blake, 2011), fish (5.5 km; Anderson et al., 2011), and hornbills (3.5 to $14.5 \mathrm{~km}$; Kitamura, 2011; Figure 4). In comparison, primates in the Palaeotropics have shorter dispersal distances of up to $1.3 \mathrm{~km}$ for macaques (McConkey, 2018) and $1.8 \mathrm{~km}$ for bonobos (Tsuji et al., 2010).

Seeds that are too large to be swallowed by bats are dispersed much shorter distances than described above, but documenting these patterns accurately has been difficult. Maximum distances of $400 \mathrm{~m}$ have been recorded for seeds spat out in ejecta or dropped by small pteropodids ( $n=9$ studies), and $7.2 \mathrm{~km}$ for large pteropodids ( $n=7$ studies). In the case of large pteropodids, these distances are still longer than those recorded for many other taxa (Figure 4), and qualifies them as long-distance seed dispersers (Cain et al., 2000). Average dispersal distances for seeds across all pteropodids and handling methods is $0-150 \mathrm{~m}$, but it is difficult to determine the frequency of these distances. While dispersal distances of defecated seeds are estimated using gut retention times and movement data, seeds that are dropped or spat out are recorded through direct observations of foraging bats or locations of feeding roosts. Documenting long flights of bats carrying fruits is difficult, and hence has only been reported rarely.

Pteropodids vary in their use of feeding roosts, and this behaviour influences the likelihood of whether seeds are deposited under or away from the crowns of parent plants. Several pteropodid species have been recorded to use feeding roosts (Table 4) and could be carrying fruit away from parent crowns regularly, regardless of food-processing behaviour. This is most often observed in small pteropodid species (Bhat, 1994; Hodgkison et al., 2003; Deshpande and Kelkar, 2015), which move seeds 37-200 $\mathrm{m}$ for processing in other trees. The largebodied Pteropus species process fruit within the crown, dropping $70 \%$ or more of seeds that are too large to be swallowed in this area, and yielding a likelihood of dispersal away from the plant crown that is dependent on the abundance of feeding bats (described above in "Fruit processing") (McConkey and Drake, 2006; Nakamoto et al., 2009; Mahandran et al., 2018).

\section{Seed Deposition and Germination}

Bats defecate in flight (Tan et al., 2000), so can theoretically disperse seeds anywhere along their foraging routes. This is particularly relevant for restoration of disturbed areas, as bats only have to pass over habitat to disperse seeds into it (Sritongchuay et al., 2014; Oleksy et al., 2015). However, use of feeding roosts concentrates seed rain in more limited areas. Smaller bodied Cynopterus species create small homogenous seed shadows, while the larger bodied Pteropus create large heterogeneous patterns (Deshpande and Kelkar, 2015). While these two genera have been recorded facilitating seed dispersal in urban areas (Corlett, 2006; Vendan and Kaleeswaran, 2011; Chan et al., 2020), human activities may impact successful seedling recruitment, e.g., due to seed deposition on unsuitable substrates inhibiting germination, or seedlings crushed by footfall due to higher human traffic.

As Pteropus and Acerodon spp. are canopy feeders, this dispersal guild may be particularly important to canopy-germinating seeds of strangler figs (Laman, 1995; 
Shanahan and Compton, 2001). However, the effects of dispersers on germination are notoriously variable among plant-animal combinations (Traveset, 1998). Pteropodid bats showed the same variable pattern in the 67 bat-plant interactions for which germination tests have been conducted (46 plant species, 25 bat species), but showed an overall tendency for neutral $(60 \%)$ or positive effects (33\%) (Table 5). Negative effects were recorded for just four interactions (5\%), with three interactions showing a decrease in germination speed, and two interactions showing a decrease in germination rate. Seeds of Ficus were most commonly tested (31 interactions), demonstrating mainly positive (14 interactions), or neutral (16 interactions) effects, with one inconclusive test. Two studies compared germination of Ficus in ejecta and faeces, and found either positive effects for seeds in faeces, or inconclusive results. A further 41 pteropodid-plant interactions were inferred to be successful based on the presence of saplings under feeding roosts.

\section{Double Mutualisms: Bats as Pollinators and Seed Dispersers of the Same Species}

Pteropodids act as both pollinators and seed dispersers (Figure 5), and are therefore potentially important "double mutualists," i.e., playing a beneficial role in two different functions (Fuster et al., 2019). Double mutualisms have been reported rarely (302 records in a review by Fuster et al., 2019), and appear to occur more commonly on islands (Olesen et al., 2018; Fuster et al., 2019). Here 138 bat-plant interactions were recorded which are potential examples of double mutualisms, involving 26 pteropodid species with 91 plant species from 36 families (Figure 6). The plant families Myrtaceae, Sapotaceae, Musaceae, Arecaceae and Anacardiaceae, in particular, may potentially benefit from double mutualisms involving several different pteropodid species across different countries. Many Pteropus species are probably double mutualists, reflecting the more generalist diet of the genus. Both bat pollination and seed dispersal have been confirmed for Musa acuminata (Itino et al., 1991; Tang et al., 2007b; Meng et al., 2012) and Madhuca longifolia (Nathan et al., 2009; Stephenraj et al., 2010; Mahandran et al., 2018), but most of these potential double mutualisms are based on fruit and flower feeding records, some of which are also confirmed seed dispersal records (Supplementary Information 2).

As many studies report non-destructive feeding behaviour, diet lists could provide a reasonable suggestion of function, especially for seed dispersal, but most of the potential double mutualisms we report require further investigation in order to confirm this functional role. Given the known examples of plant self-incompatibility (Bumrungsri et al., 2009), flower destruction (Gumal, 2001), and fruit consumption at parent trees (McConkey and Drake, 2006), pteropodid diet on its own cannot, and should not, be used to confirm ecological roles. While seed dispersal potential can be inferred from foraging movements, more in-depth research is needed to determine whether a pteropodid species serves as a pollinator or flower predator; e.g., P. vampyrus in Sarawak is reported to destructively consume whole flowers of Madhuca motleyana (Gumal, 2001), and Cynopterus spp. appear to have limited effectiveness as true pollinators despite non-destructive feeding

TABLE 5 | Summary of results of germination tests on seeds dispersed by pteropodids.

\begin{tabular}{|c|c|c|c|c|c|}
\hline \multirow[t]{2}{*}{ Pteropodid genus } & \multicolumn{4}{|c|}{$\begin{array}{l}\text { Number of plant species and the recorded effects on } \\
\text { germination speed or rate }\end{array}$} & \multirow[b]{2}{*}{ Source/Study } \\
\hline & Positive & Neutral & Negative & Inconclusive & \\
\hline Balionycteris & & 5 & & 2 & Hodgkison et al., 2003 \\
\hline Chironax & & 1 & & & Hodgkison et al., 2003 \\
\hline Cynopterus & 1 & 7 & 1 & & $\begin{array}{l}\text { Shilton et al., 1999; Hodgkison et al., 2003; Tang et al., } \\
\text { 2007a, Tang et al., 2008, 2012; Mahandran et al., } 2018\end{array}$ \\
\hline Dyacopterus & & 2 & & & Hodgkison et al., 2003 \\
\hline Eidolon & 4 & 23 & & & Webala et al., 2014 \\
\hline Epomophorus & 3 & 4 & 1 & & $\begin{array}{l}\text { Djossa et al., 2008; Voigt et al., 2011; Jordaan et al., 2012; } \\
\text { Helbig-Bonitz et al., } 2013\end{array}$ \\
\hline Micropteropus & 1 & & & & Djossa et al., 2008 \\
\hline Myonycteris & 1 & & & & Djossa et al., 2008 \\
\hline Nanonycteris & 1 & & & & Djossa et al., 2008 \\
\hline Nyctimene & 1 & & & & Utzurrum and Heideman, 1991 \\
\hline Ptenochirus & 1 & & & & Utzurrum and Heideman, 1991 \\
\hline Pteropus & 7 & 29 & & & $\begin{array}{l}\text { Entwistle and Corp, 1997; Bollen and van Elsacker, 2002; } \\
\text { Goveas et al., 2006; Vendan and Kaleeswaran, 2011; } \\
\text { Scanlon et al., 2014; Chen et al., 2017; Oleksy et al., } 2017\end{array}$ \\
\hline Rousettus & & 9 & 2 & & $\begin{array}{l}\text { Izhaki et al., 1995; Tang et al., 2007a; Mahandran et al., } \\
\text { 2018; Andrianaivoarivelo et al., } 2011\end{array}$ \\
\hline Unidentified & 1 & & & 1 & Utzurrum, 1995; Djossa et al., 2008 \\
\hline Total & 21 & 79 & 4 & 3 & \\
\hline
\end{tabular}




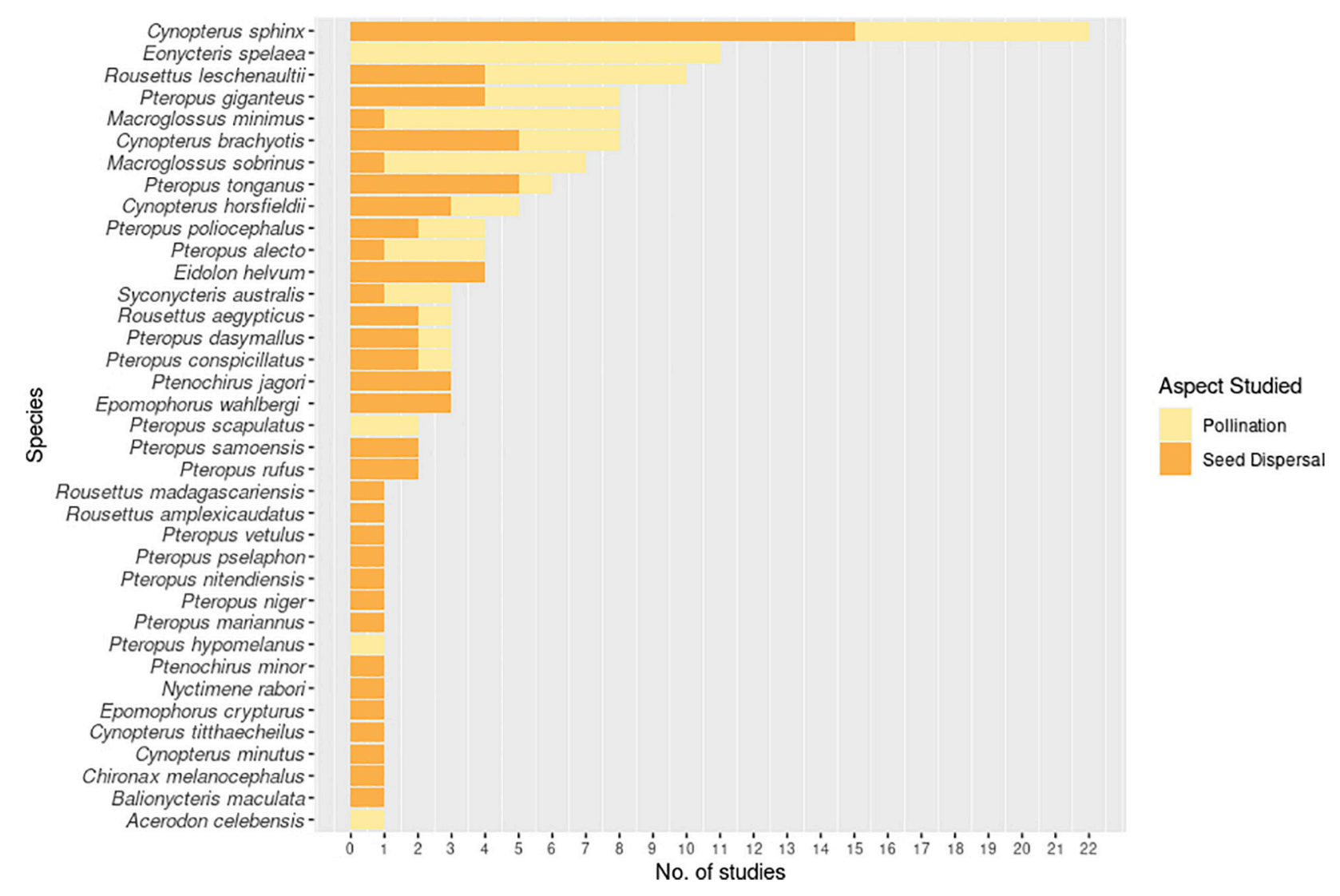

FIGURE 5 | Number of studies investigating the roles of specific pteropodid species as pollinators or seed dispersers during $1985-2020$.

(Stewart and Dudash, 2017). However, flower consumption does not necessarily prevent successful pollination from happening for an individual plant, as long as some gynoecia remain intact and have a chance to receive conspecific pollen in the process (Elmqvist et al., 1992; Nathan et al., 2009; Stephenraj et al., 2010; Toyama et al., 2012).

It is also important to note that some plant species that could potentially benefit from both pollination and seed dispersal by bats (e.g., Agave americana, Diospyros kaki, Eriobotrya japonica, Mangifera indica, Manilkara zapota, Musa acuminata, Prunus armeniaca, P. persica, Psidium guajava, and many Syzigium species - although, pollination for all except $M$. acuminata is currently still unconfirmed) are commercially important trees, commonly planted in gardens, orchards and plantations - and as such, bat consumption of these fruits can be perceived as a form of ecosystem disservice (Zhang et al., 2007; Shackleton et al., 2016).

\section{Intra-Specific Variation in Ecological Function}

Variation among individuals is important for maintaining diverse seed dispersal and pollination roles at the population level (Zwolak, 2018; Schupp et al., 2019). To our knowledge, intra-specific or intra-population variation in pteropodids has only been described for movement distances, although the independent movement trajectories that individuals from a single roost display (e.g., Tsoar, 2011; Harten et al., 2020; Toledo et al., 2020; Welbergen et al., 2020) could mean considerable variation in foraging choices as well (e.g., Scholesing et al., 2020). Future studies might reveal broad variation in food choice, seed dispersal, and pollination among individuals. Of the 160 studies on pteropodid foraging movements (Supplementary Information 5), intra-population variation in movement distances was described for five genera, and for three of these (Cynopterus, Pteropus, and Rousettus) female bats moved further than males. Sexually immature Melonycteris moved further than adults, and seasonal and habitat differences in ranging distances were found for Eidolon helvum and Rousettus aegyptiacus.

\section{Function of Pteropodids at the Community Level}

The role that pteropodids fulfil within the wider pollinator and seed disperser communities is poorly understood. Twenty-six studies have investigated either pollination or seed dispersal roles of bats across multiple plant species, and compared these roles with other animals in the community. While feeding assemblages have been documented for individual plant species, particularly to document pollination of cultivated plants, we cannot interpret the broader community roles from these 


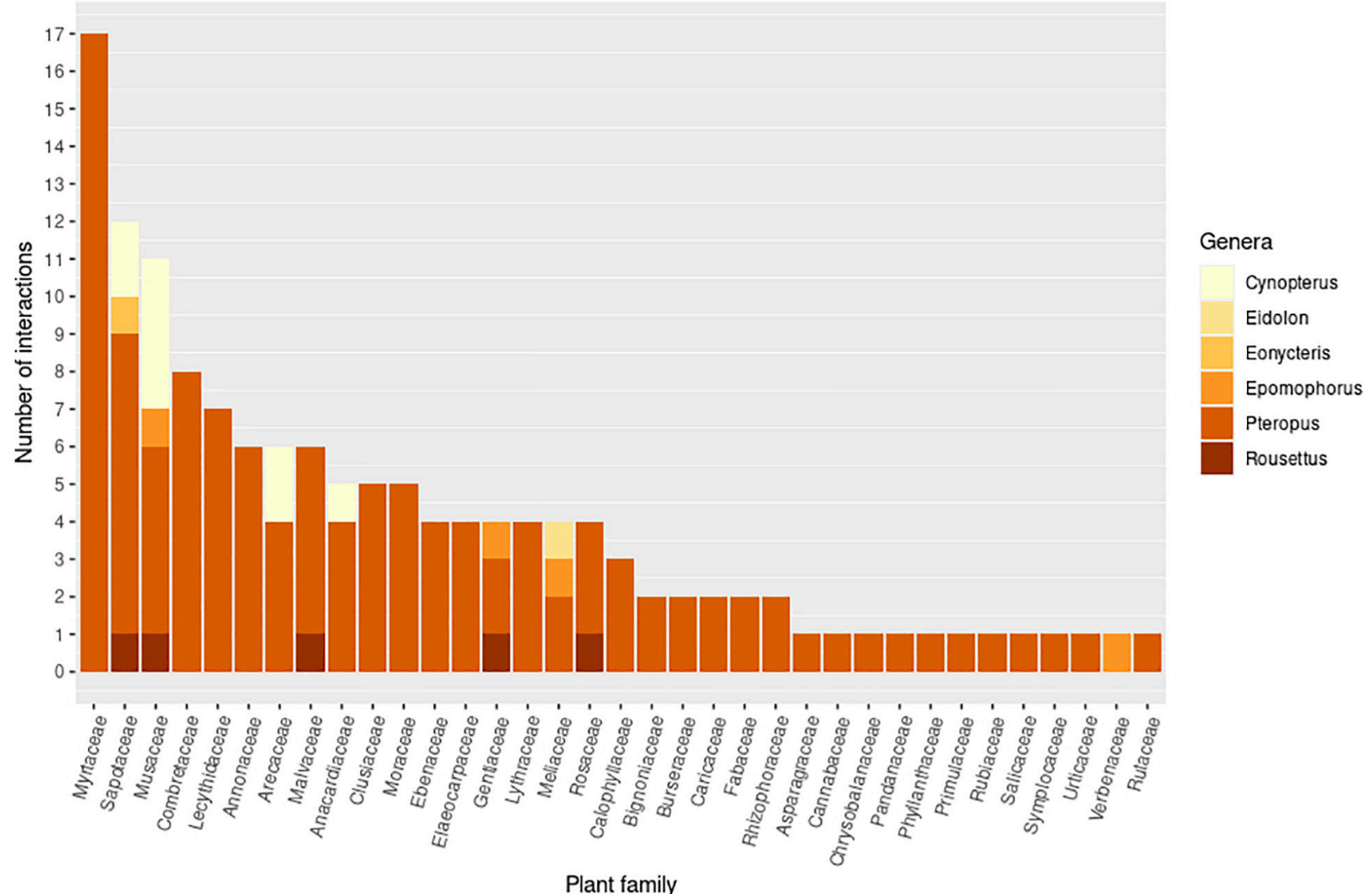

FIGURE 6 | Pteropodid-plant interactions that are potentially double mutualisms, in which a pteropodid species might act as both pollinator and seed disperser for the same plant species. Double mutualisms were assessed at the species level for both plants and bats. The graph shows the number of species-species interactions within each plant family and pteropodid genus. Only families with more than one interaction are shown. Plants in an additional 13 families were recorded for overall pteropodid diet, but only one interaction was recorded for each, and thus not included here.

studies. In the Tongan archipelago, Pteropus tonganus was the only effective seed disperser of $57 \%$ of the plant species that it consumed, an importance resulting from the prehistoric extinctions of other large dispersers (McConkey and Drake, 2015). The importance of Pteropus on islands is also reflected in their large diet breadth. Pteropus tonganus and P. samoensis interacted with $59 \%$ of the forest tree species on Samoa, and about $25 \%$ of the woody plant species in Mauritius have their seeds dispersed by $P$. niger (Florens et al., 2017), while $P$. ornatus, $P$. tonganus, and $P$. vetulus were found to be far more efficient seed dispersers compared to introduced rats on New Caledonia (Duron et al., 2017). In the Philippines, birds dispersed a higher diversity and number of seeds into successional forests (Ingle, 2003; Gonzales et al., 2009), and there was substantial overlap in fruit consumption between birds and bats especially during some seasons (Gonzales et al., 2009). Given the depauperate frugivore and pollinator communities on islands, pteropodid bats are likely to play dominant, keystone roles within these systems wherever their populations have not been decimated by hunting or pest control (Cox et al., 1991). The high Pteropus diversity across islands and probable origin of the genus from the islands of Wallacea (Tsang et al., 2020) suggest a long evolutionary history in island ecosystems, which could be reflected in the ecological roles they perform there.

Within continental habitats, the importance of bat pollination and seed dispersal have been studied at the community level in Australia and Thailand (e.g., Birt, 2004; Sritongchuay et al., 2019), but no community-wide studies have been conducted in most regions. In a dipterocarp forest in Peninsular Malaysia, Pteropus vampyrus occurred in a different module of a seed dispersal network compared to smaller bats, indicating they tended to interact with a different subset of plant species (Ong, 2020). The large bats shared a module with other large mammals, including elephants and frugivorous primates, while the smaller bats occurred in the same module as squirrels and rats. Pteropus vampyrus was found to be among the 10 most important seed dispersers in the community, with smaller bats also playing an important community role. A study focused on bat-used fruit resources in a Malaysian rainforest found that $56 \%$ of the resources used by bats were also consumed by primates, civets or squirrels, but the ecological roles were not evaluated (Hodgkison et al., 2003).

In Peninsular Malaysia and Thailand, small pteropodids are important Sonneratia pollinators in mangroves (Nor Zalipah et al., 2016; Stewart and Dudash, 2016, 2017; Nuevo Diego, 2018; 
Nuevo Diego et al., 2019), with Pteropus spp. likely playing a similar role possibly supplemented by seed dispersal (Gumal, 2001; Weber et al., 2015; Wee et al., 2017). Since mangrove health can be crucial for maintaining healthy functioning coral reefs (Mumby, 2006; Yates et al., 2014; Loh et al., 2018; Friess et al., 2020), this suggests that the ecological importance of pteropodids extends beyond terrestrial and even coastal/estuarine ecosystems to potentially influence the health of marine ecosystems too. To fully understand the importance of pteropodid bats at the community level, we need broad studies across a greater breadth of ecosystems. Because pteropodids are important for both pollination and seed dispersal, studies focusing on a single function will underestimate their importance to ecosystems, and hence ambitious studies are needed that measure pollination and seed dispersal jointly.

Population abundance is an important predictor of functional importance for a broad range of animals including bats (Bauer and Hoye, 2014; Winfree et al., 2014; Simmons et al., 2019; Laurindo et al., 2020). Even animals that rarely disperse seeds can be important contributors to community-wide seed dispersal if they occur in very abundant populations, as has been documented for ducks (Soons et al., 2016) and proposed for the now extinct passenger pigeon (Webb, 1986). Hence, the sheer abundance of some pteropodid populations (Roberts et al., 2012; van Toor et al., 2019) combined with their effectiveness as pollinators and seed dispersers suggest vital functional roles within the ecosystems where they occur. The fact that many of these abundant pteropodid species are also migratory, thereby promoting long-distance dispersal of pollen and seeds (Bauer and Hoye, 2014), creates an even greater urgency in understanding the community-level roles of pteropodids.

\section{Assessing the Ecosystem Services for Humans Provided by Pteropodids}

Although the majority of studies on the ecological roles of pteropodids have focused on seed dispersal, attempts to document the benefits these bats bring to humans have more frequently focused on pollination, likely because such benefits are more direct and can be more easily quantified in economic terms. The majority of pollination studies have documented the ecosystem services provided by bats for major fruit crops in Asia such as durian (Durio zibethinus; Bumrungsri et al., 2009; Acharya et al., 2015; Aziz et al., 2017c; Sheherazade et al., 2019), petai (Parkia spp.; Bumrungsri et al., 2008), midnight horror (Oroxylum indicum; Sritongchuay et al., 2008), and madhuca (Madhuca longifolia; Nathan et al., 2009; Stephenraj et al., 2010), with some Australian research focusing on important timber species (e.g., Bacles et al., 2009). The durian pollination services from pteropodids in Sulawesi, Indonesia alone have been valued at $\$ 117 \mathrm{ha}$ /fruiting season or USD 450,000 for a single village (Sheherazade et al., 2019). The only study to place a financial value on seed dispersal was for Eidolon helvum and its role in reforestation in Ghana. van Toor et al. (2019) estimated that bats contributed a total annual gross revenue of $\$ 11,939$ to $\$ 858,068$ per bat colony depending on season and area. In an unusual case, the fruit foraging behaviour of Cynopterus and Pteropus in mixed-fruit agricultural landscapes in India was perceived by farmers to be beneficial (Deshpande and Kelkar, 2015); the bats aggregate cashew (Anacardium occidentale) and Areca palm nuts in accessible places, which reduces the labour required for collection. In addition, their pollination service was recognised for bananas (Musa spp.) and kapok (Ceiba pentandra), so that overall, farmers perceived that bats brought more benefits than the losses through crop raiding.

Pteropodids have also been implicated in potential ecosystem disservices to humans through their consumption of agricultural fruits (Zhang et al., 2007; Aziz et al., 2016) and the dispersal of exotic plants (Corlett, 2005; von Döhren and Haase, 2015; Vaz et al., 2017; Chan et al., 2020). As such, future approaches to assessing, quantifying and valuing the ecological roles of pteropodids should attempt to more be more holistic in including both services and disservices (Friess et al., 2020).

\section{Threats to the Ecological Roles of Pteropodids}

Of the 201 pteropodid species to date, 189 have been assessed by the IUCN (2020), such that $37 \%$ are currently threatened (7 species are "Critically Endangered," 27 species are "Endangered," 36 species are "Vulnerable") and $48 \%$ are of "Least Concern;" $9 \%$ of species are "Data Deficient" (Figure 7). However, caution must be exercised when using the assigned Red List status as sole indicator of species extinction risk. The status of many pteropodids are poorly known particularly in more localised contexts, and delays in communicating research result in outdated assessments. Furthermore, pteropodids found on islands pose special challenges when applying the IUCN's habitatbased criteria of extent of occurrence (EOO) and area of occurrence (AOO) to assess status (Mildenstein, 2020). Finally, while "common" pteropodids are studied more than "threatened" species at a rate of 5:1 (Mildenstein, 2012), "common" bat species, particularly those deemed as low conservation priorities based on their widespread distribution at a regional level, can be misinterpreted as not threatened at a country level. This can sometimes conflict with national-level species assessments that have not been captured or reflected by the IUCN Red List in a timely manner; e.g., Pteropus hypomelanus and $P$. vampyrus are both classified as "Endangered" in Peninsular Malaysia (PERHILITAN, 2017), but are both only listed as "Near Threatened" by the IUCN Red List (Bates et al., 2008; Tsang, 2020).

Another problem with looking at IUCN species assessments in isolation is that such assessments do not reflect the functional importance of many common and abundant species (Figure 5) at an ecosystem or landscape level (Redford et al., 2013; Baker et al., 2018). Since pteropodids are crucial for introducing seed rain into cleared areas and maintaining plant gene flow amongst forest fragments (Sritongchuay et al., 2014; Oleksy et al., 2015; Lim et al., 2018; van Toor et al., 2019; Chan et al., 2020), their disappearance could potentially disrupt reforestation and regeneration processes (Castillo-Figueroa, 2020). Modifications 


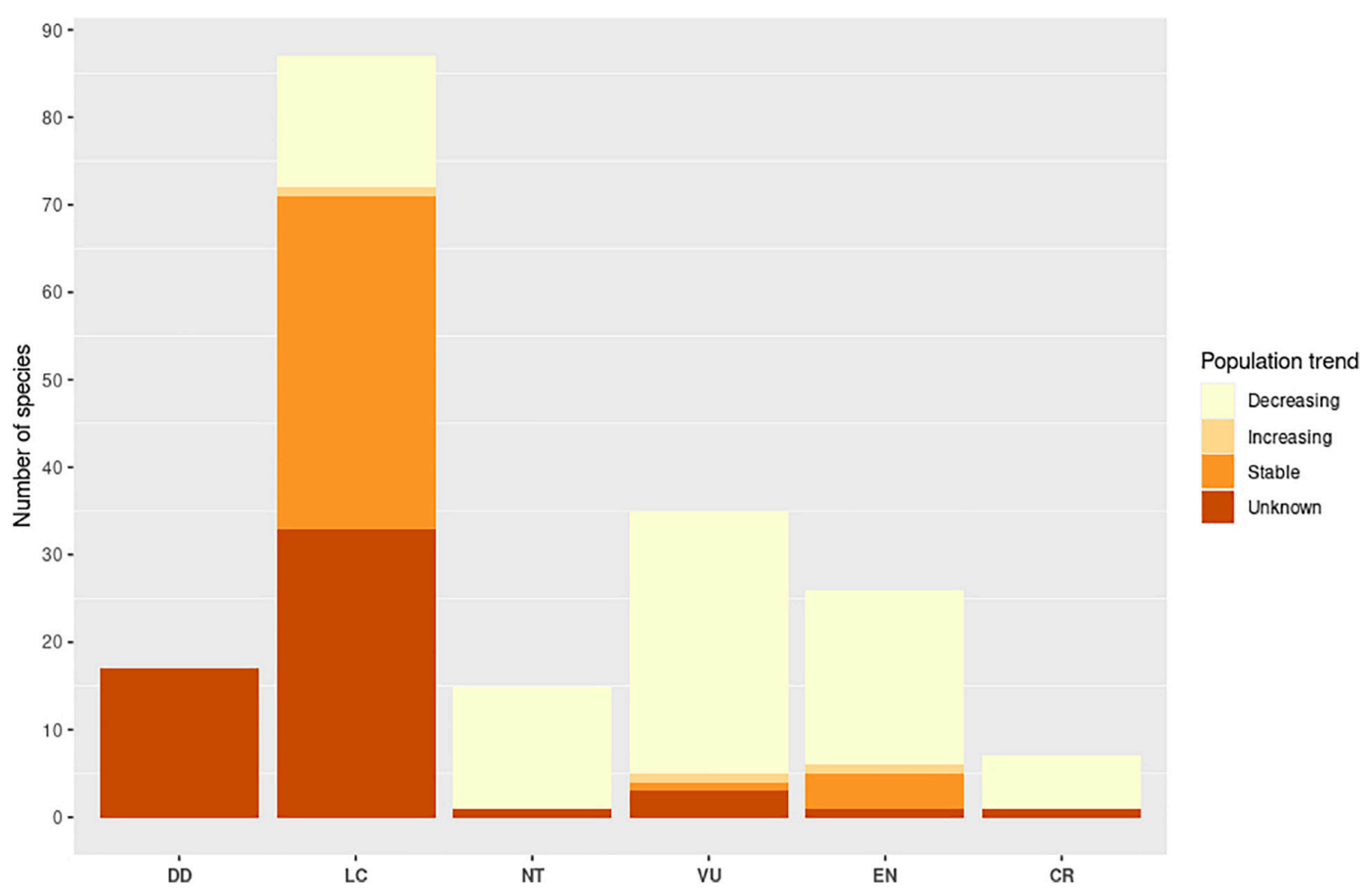

FIGURE 7 | IUCN Red List status and associated population trends of all assessed pteropodids (2020).

of the frugivore community (through logging or hunting of birds and terrestrial mammals) in the Neotropics have already been shown to reduce seed removal at the community level, leading to reduced plant recruitment and sapling density (Boissier et al., 2020). Similar effects can be expected for the Palaeotropics (Osuri et al., 2020), and it is crucial for such assessments to include pteropodids.

Comprehensive reviews have identified a number of major threats to pteropodids (Mickleburgh et al., 1992; Jones et al., 2009; O'Shea et al., 2016; Frick et al., 2019). These include direct and indirect anthropogenically caused mortality. Logging, agriculture (commercial and private or community-based), and hunting were reported by the Red List to present major threats to pteropodids (Supplementary Information 7), while fire and pollution have emerged as more recent threats. The following specific drivers are likely to cause major disruptions to pteropodid-plant interactions and their associated ecosystem functions.

\section{Hunting and Harvesting for Consumption and Trade}

Bat hunting is widespread across the Old World, affecting about $50 \%$ of pteropodid species across 24 pteropodid genera, and particularly prevalent on the large pteropodids in Southeast Asia, and to a lesser extent Africa (Struebig et al., 2007; Epstein et al., 2009; Mildenstein et al., 2016), having already caused the extinction of several Pteropus species on islands (Jones et al., 2009; Mildenstein et al., 2016). Bats are hunted for a variety of different reasons, including for bushmeat consumption (either for subsistence or as a perceived delicacy), medicinal value, trade, recreation, and for the decorative and currency values of their teeth (Mildenstein et al., 2016; Lavery and Fasi, 2019). However, hunting for consumption remains the most widespread reason. While bat meat may serve as a necessary source of protein for certain impoverished communities (Mildenstein et al., 2016), elsewhere it is prized as a high-value and high-status meat costing more than poultry (Mohd-Azlan, pers. comm.; Jenkins and Racey, 2008) when it is sold on the black market (e.g., Pteropus mariannus is sold by poachers for as much as 150 USD on Guam; Mildenstein, unpubl. data).

Hunting causes changes to bat foraging and roosting behaviour, as well as population declines (Mildenstein et al., 2016). As the ecosystem roles of Pteropus become disrupted when their population abundance is too low, their functional extinction in the Asia-Pacific region - where their ecological importance in many countries is still poorly understood - can become a concern long before actual species or population extinction (McConkey and Drake, 2006). Similarly, Eidolon helvum travels the longest distance of any known mammal in Africa (van Toor et al., 2019), and its annual transboundary migration likely makes it the most important long-distance disperser of seeds and pollen on the continent (Richter and Cumming, 2008) yet it is intensively hunted whenever it is found in abundance (Mildenstein et al., 2016; O'Shea et al., 2016). Although most bat hunting and trade is local rather than international, hunting pressure selectively targets the large pteropodids (Mildenstein et al., 2016) that function as the most crucial and often sole 
long-distance dispersers (Elmqvist et al., 1992; Fleming and Racey, 2009; McConkey and Drake, 2015), which should be a cause for serious concern (Stoner et al., 2007).

These examples underscore how conservation action is imperative even for abundant and/or common species due to their disproportionately important roles in maintaining ecosystem health (Redford et al., 2013; Florens et al., 2017; Baker et al., 2018; Laurindo et al., 2020). The majority of assessed pteropodid species are considered Least Concern by the IUCN Red List, with conservation efforts skewed towards highly threatened species. Yet this approach overlooks common and less threatened species that are often more vulnerable to hunting due to their hyperabundant populations (e.g., Rousettus amplexicaudatus in the Philippines), which may lead to a "Passenger Pigeon Fiasco" effect whereby a common and widespread species went extinct over time due to continuous overhunting and the lack of effective statutory conservation attention (Tanalgo and Hughes, 2019).

\section{Killings and Persecution Driven by Conflict and Negative Perceptions}

Negative public perceptions of bats have been documented as remnant and long-standing socio-cultural values of Western, Eurocentric cultures that increasingly permeate international media reporting on bats (Thiriet, 2010; Lunney and Moon, 2011; Kingston, 2016). However, specific and localised negative perceptions of bats can also arise through conflict interactions such as crop-raiding and shared living space, often exacerbated by low awareness of bats' ecological importance (Larsen et al., 2002; Kung et al., 2015; Aziz et al., 2016, 2017a; O’Shea et al., 2016). In particular, intentional killings of bats for crop protection purposes can result in multiple species being intensively culled at very high numbers (O'Shea et al., 2016), with the national cullings of Pteropus niger on Mauritius being the most recent extreme example (Florens and Baider, 2019). Such massive population reductions are especially damaging at the ecological level, because it directly affects the role of such a keystone island species in maintaining native forests (Florens et al., 2017). Ironically, persecution and culling of pteropodids can also negatively impact the very commercial crops that rely on these bats for successful pollination and fruit production, such as durian (Aziz et al., 2016).

These issues are further compounded by misguided fear over speculated disease risks, which are often sensationalised and exaggerated by the media (Thiriet, 2010; Schneeberger and Voigt, 2016; López-Baucells et al., 2018; Tuttle, 2018). The current COVID-19 pandemic is the latest and worst example of this problem, with premature speculations in the media misleadingly associating the disease with bats, i.e., assuming or implying all bats to be a direct source of human infection (as opposed to one insectivorous genus merely being a possible evolutionary origin of the virus currently causing the disease), stoking even more public backlash (Rocha et al., 2020; Tuttle, 2020; Zhao, 2020). This has even resulted in violent and cruel attempts to cull or eradicate bats in a completely misguided effort to control the disease, despite the fact that the animal host for the SARS-CoV-2 virus is still unknown (Bittel, 2020; Lu et al., 2021).

\section{Habitat Loss and Disturbance}

Habitat loss and disturbance affect both roosting areas and food sources for pteropodids. Deforestation is especially a concern in the tropics (Jones et al., 2009; Meyer et al., 2016), and a decreasing abundance of native food plants can drive pteropodids to feed more on introduced exotics in human-dominated areas (Luskin, 2010; Mildenstein, 2012; Aziz et al., 2016; Lim et al., 2018). This could lead to ecosystem disservices (Zhang et al., 2007; von Döhren and Haase, 2015; Vaz et al., 2017) such as the propagation of invasive plants (e.g., Voigt et al., 2011; Jordaan et al., 2012), and also crop-raiding of commercially cultivated fruits (Aziz et al., 2016), but even simple interventions to address habitat degradation, such as invasive alien plant control in native forests, can improve foraging habitat for pteropodids and therefore potentially reduce crop raiding (Krivek et al., 2020).

Land-use change in surrounding areas is also known to alter pollination networks in mixed-fruit orchards, affecting fruit production (Sritongchuay et al., 2019). Moreover, cave-roosting pteropodid pollinators such as Eonycteris and Rousettus are particularly vulnerable to limestone quarrying activities by the cement and marble industries, land-clearing around caves, and disturbance by human visitors (Clements et al., 2006). The lack of suitable cave roosts can thus have a direct detrimental impact on pollination services, affecting economically significant fruit industries (Sritongchuay et al., 2016).

Habitat modification, fragmentation and urbanisation are already known to affect pollination and seed dispersal by phyllostomid bats (Meyer et al., 2016; Regolin et al., 2020); e.g., in the Neotropics, frugivorous bats avoid areas with too much light, and feed less (on both fruit and nectar) in these areas (Lewanzik and Voigt, 2014). However, the impact of such processes on the ecological roles of pteropodids is still poorly understood. In particular, more studies are needed to document the full seed dispersal cycle, from seed deposition all the way through to plant recruitment, and how this is affected by habitat alteration (Meyer et al., 2016).

\section{Invasive Species}

Invasive species are a significant threat to island-dwelling pteropodids, but the impacts of invasions are not well studied (Welch and Leppanen, 2017). Non-native cats, dogs, rats, ants and snakes prey on pteropodids (e.g., Vincenot et al., 2017a; Oedin et al., 2021), but how this threatens pteropodids' population stability and behaviour is mostly unknown. On Guam, predation by the invasive brown tree snake (Boiga irregularis) is thought to have contributed to the extinction of the endemic Pteropus tokudae, and partially to declines in P. mariannus (Wiles, 1987; Mildenstein, 2020). The snake has also caused the extirpation of most forest bird species on Guam (Savidge, 1987), which, in turn, has disrupted plant recruitment (Rogers et al., 2017). How this reduction in fruit bat population size and behaviour has affected the island's ecosystem, in terms of loss of ecological roles, has not been investigated. Invasive yellow crazy ants (Anoplolepis gracillipes) on Christmas Island disrupt the activity budgets of Pteropus melanotus (Dorrestein et al., 2019), but impacts on foraging and movement behaviour have not been documented. 
Invasive species also have indirect effects on pteropodids when they alter habitats either through overgrazing (such as by deer and goats), competition for food resources (e.g. by macaques; Reinegger et al., 2021), or through the spread of non-native plants (Welch and Leppanen, 2017). The effect this has on foraging movement and ecological roles of pteropodids will depend on whether they avoid invaded areas (Krivek et al., 2020) or are attracted to them (Luskin, 2010), and there have not been enough studies to quantify responses.

\section{Climate Change}

Climate change can threaten pteropodids through increased frequency and intensity of extreme weather events such as cyclones and intense heat/droughts (Welbergen et al., 2008; Jones et al., 2009). Cyclones are known to have an impact on endemic Pteropus spp. on Indian Ocean and Pacific islands, drastically reducing populations (e.g., $80-90 \%$ for some island Pteropus) and their food sources, and leaving bats vulnerable to increased hunting pressure from humans, conflict due to greater foraging in anthropogenic landscapes, or predation from domestic animals (Craig et al., 1994; Grant et al., 1997; McConkey et al., 2004; Esselstyn et al., 2006; O'Shea et al., 2016; Scanlon et al., 2018). Again, the negative impacts on island ecosystems are likely to be disproportionately high, particularly since the ecological roles of island Pteropus cannot be replaced by other animals (McConkey and Drake, 2015; Duron et al., 2017).

Australian Pteropus are known to regularly die en masse from extreme heat stress due to ambient temperatures exceeding $42^{\circ} \mathrm{C}$ (Welbergen et al., 2008; Jones et al., 2009; Daly, 2020), and the most recent bushfires associated with such an extreme weather condition (van Oldenborgh et al., 2020) will likely have farreaching and long-lasting impacts on the Myrtaceae-dominated forests that rely heavily on pteropodid pollination (Birt, 2004; Boulter et al., 2005; Bacles et al., 2009; Reuters, 2019). Climate change could also lead to increased and intensified precipitation that would depress foraging activity, and perhaps even cause pups to starve or be abandoned, whilst sea level rise could inundate coastal roost sites (Jones et al., 2009).

Temperature changes could alter the timing of flowering and fruit development which could interfere with pollination and seed dispersal relationships (Sherry et al., 2007), particularly for migratory species that follow resource pulses (see Foraging Landscapes section). Pteropodids locate flowers and fruits using olfaction primarily, but the volatile organic compounds (VOCs) that they use as a guide could be altered by climate change (Yuan et al., 2009). However, while impacts of climate change are already being predicted for Neotropical pollination (e.g., Zamora-Gutiérrez et al., 2021) and seed dispersal (e.g., bird dispersal of a palm; Sales et al., 2021), potential effects on the ecological roles of pteropodids have not yet been studied.

\section{Knowledge Gaps and Future Research Directions}

Although research efforts on pteropodid-plant interactions have increased markedly over the last three decades (Figure 8), the gaps in our knowledge of their ecological roles are large (Supplementary Information 8). We propose eleven key priorities for future studies and other efforts to bolster our understanding of bat-plant interactions in the region (Table 6). Of the 201 pteropodid bat species to date, only $37 \%(n=75)$ have been studied, with the majority of research focused on a few common species. Documenting the role of common or widely distributed species that could be playing major ecological roles (e.g., Pteropus vampyrus, Gumal, 2001; Eidolon helvum, van Toor et al., 2019) is important, but we have not yet sufficiently understood or recognised the importance of abundance per se, in order to ensure that populations of highly abundant species are maintained at appropriate levels. However, it is also vital to understand the roles of rare species that have dwindling populations. These population declines are often a direct result of human persecution (Aziz et al., 2016; Mildenstein et al., 2016; O'Shea et al., 2016), and strong arguments are required to bolster support for species conservation - especially for those deemed "common" and "abundant" (Redford et al., 2013; Baker et al., 2018).

Most of the countries with highly diverse pteropodid assemblages have had few studies, hindering our understanding of how these diverse bat communities are structured with respect to their ecological roles. The highest diversity of pteropodids is found in Indonesia (77 species), Papua New Guinea (36 species), and India (13 species) (Figure 9), but only India features in the five countries that have had more than 20 studies published on pteropodids, while African bats have been particularly poorly studied. Forested and cultivated habitats have received the most research effort, yet pteropodids inhabit other habitats, such as caves and urban areas, where more research attention is required.

A paucity of studies on the ecological roles of pteropodids has hindered a broader understanding of their importance. The majority of studies we report were focused only on diet, followed by foraging movement. Relatively few studies have directly investigated the roles played by pteropodids in pollination and seed dispersal (Figure 1). Pteropodids in Africa, the Mediterranean and Papua New Guinea are especially poorly studied in these aspects. Also, even with pteropodid species for which some documentation of diet exists, more comprehensive and detailed dietary records are still needed.

A research focus on pollination of cultivated plants is an important conservation need for countering persecution and negative opinions against bats. Yet robust empirical evidence is still lacking for confirming the role of bats in pollinating more commercially important plants, even though some of these plants have been erroneously cited as examples of bat pollination services (e.g., Artocarpus, Palaquium; Lee et al., 2002). Bat diet, flower visitation and pollen load identification/quantification, on their own, are insufficient for determining pollination success. In order to confidently determine pollinator effectiveness and pollination services of individual pteropodid species, investigations must employ appropriate exclusion experiments, identify relevant floral biology traits (including timings of anther dehiscence and stigma receptivity), document bat feeding behaviour, assess successful pollen transfer, and/or analyse the effect of bat visits on mature fruit set; without the use of these methods, any conclusions about the pollinating 


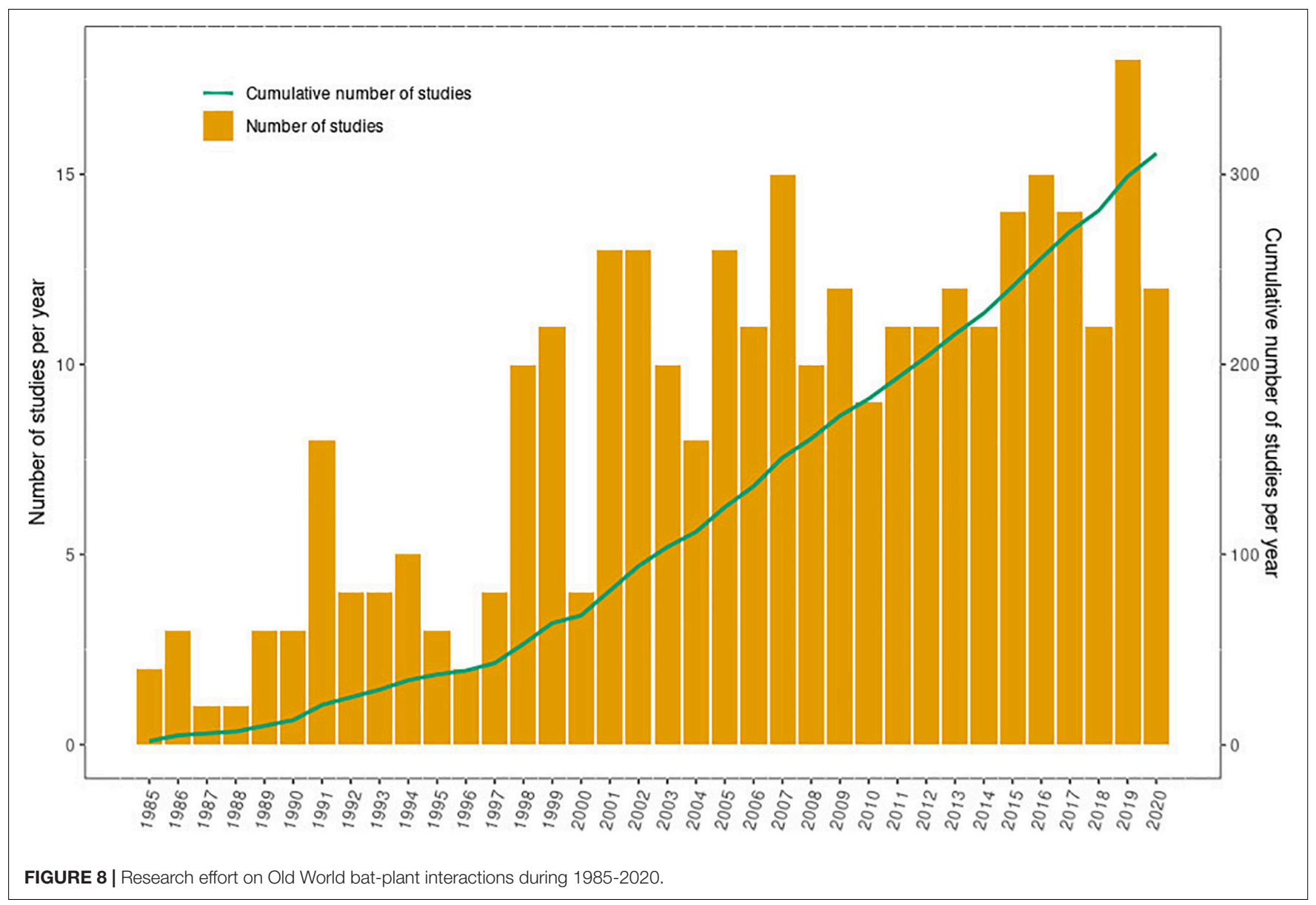

TABLE 6 | Directions for future research directions and other efforts to bolster progress on understanding pteropodid-plant interactions.

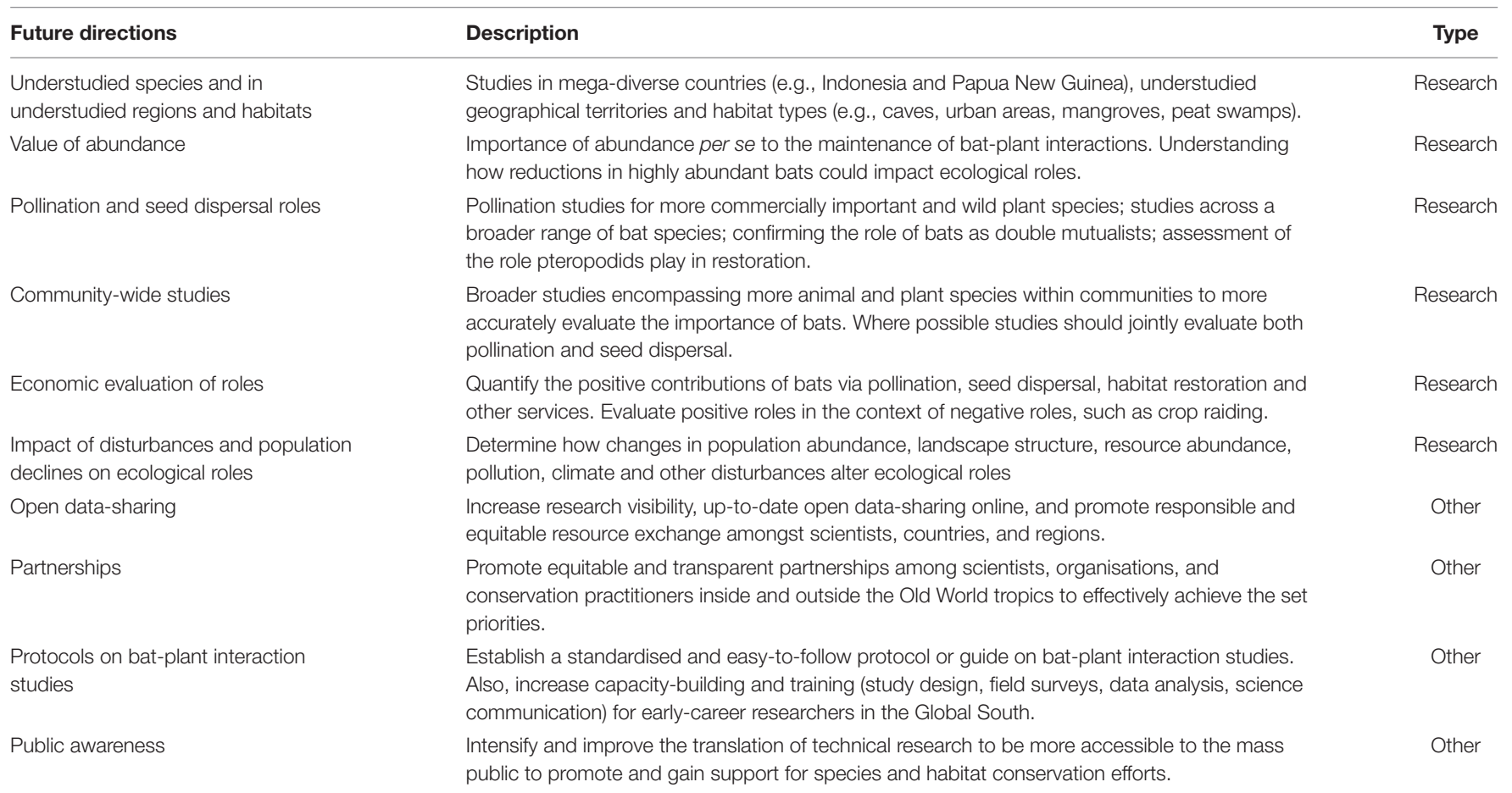




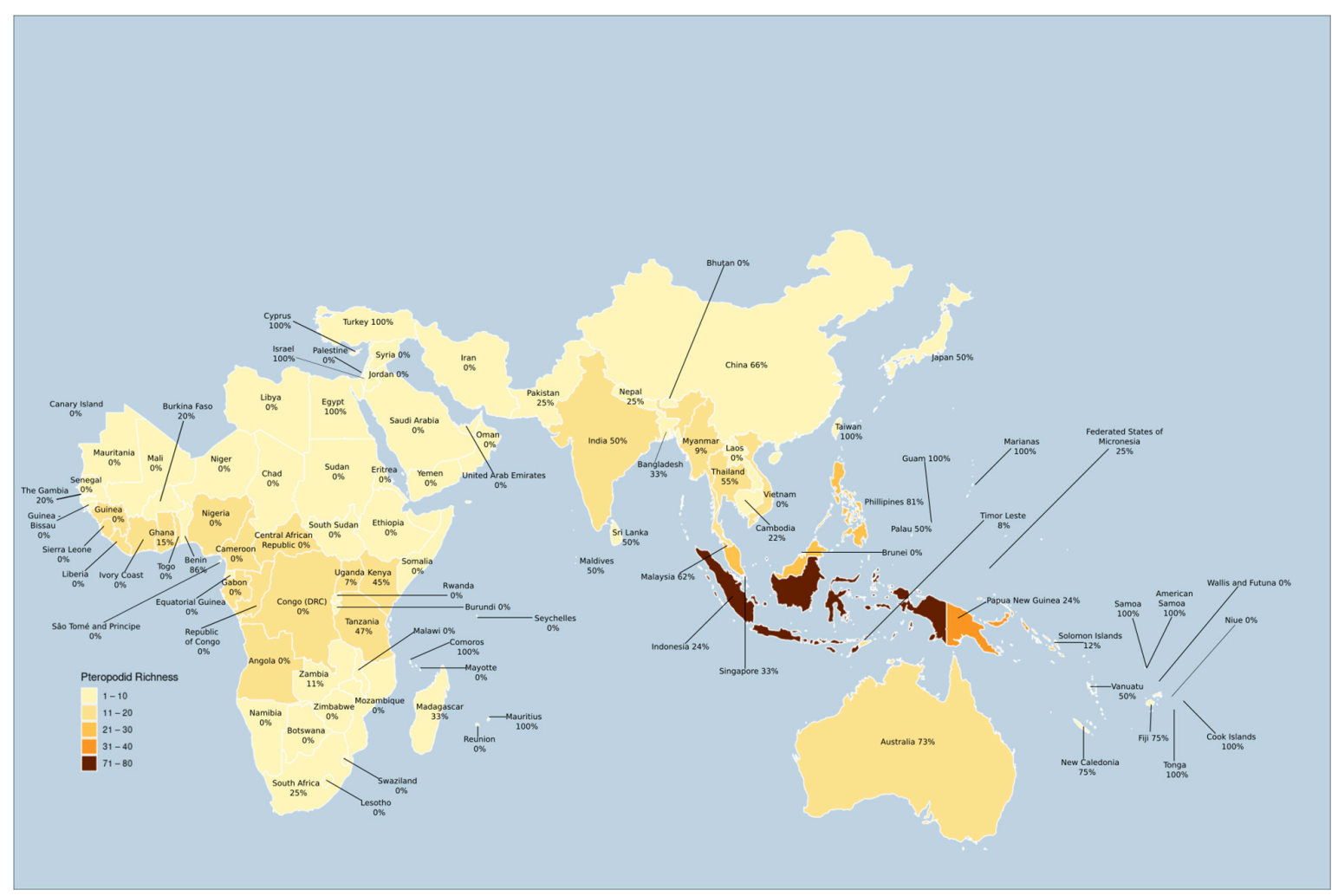

FIGURE 9 | Proportion of studied pteropodid species per country during 1985-2020 (map excludes countries with no pteropodid occurrence).

roles of bats are premature and potentially inaccurate, and therefore cannot be made.

There remains a paucity of data on pteropodid pollination of wild plants. This knowledge deficit must be addressed to better appreciate the role of bats at the community level, and to understand their roles as double mutualists for a variety of ecosystems. Indeed, bat pollination could well be occurring for many plant species that are not currently known or suspected to be chiropterophilous, especially since some Pteropus species forage diurnally (Pierson et al., 1996; Richmond et al., 1998; Lavery et al., 2020; Aziz, pers. obs.). Broader studies are required to compare bats with other mutualists (Ong, 2020; Ingle, 2003; McConkey and Drake, 2015); where feasible, such studies should integrate the combined roles of pollination and seed dispersal to more accurately determine the importance of pteropodids. Studies quantifying the ecosystem services and economic contributions of the large-bodied pteropodids most intensively threatened by hunting and conflict (e.g., Pteropus spp. and Eidolon spp.) are a particularly critical and urgent need.

The frequent conflict between pteropodids and people requires economic assessments of ecosystem services and disservices to fairly and accurately represent the losses and gains that pteropodids generate. This can be done by incorporating cost-benefit analyses into assessments of such bat-plant interactions involving commercial fruit growers. Conflict was the least studied topic in our review (12\% of studies) (Figure 1), only conducted in 14 countries, and only three of these (Japan,
Kenya and Mauritius) also have studies on the ecological roles of the bats. An exception to this imbalance is Mauritius, where supposed losses of cultivated fruit to foraging Pteropus niger has resulted in two culls by the Government of Mauritius, causing the deaths of over 90,000 bats (Vincenot et al., 2017b). Researchers here have noted the ineffectiveness of culls (Florens and Baider, 2019), calculated minimal fruit losses to the bats (Oleksy et al., 2018), documented the ecological roles of the species (Nyhagen et al., 2005; Florens et al., 2017), and attempted to identify appropriate mitigation methods to reduce economic loss (Oleksy et al., 2018; Krivek et al., 2020). Such efforts are urgently needed but still lacking in many regions, such as Southeast Asia, East Asia, West Africa, South Africa, and Papua New Guinea. Negative perceptions of bats might be countered by more studies on the roles pteropodids play in pollinating important plants, or restoring habitats via seed dispersal. This restoration role is well recognised in Neotropical regions but represented by less than five studies for pteropodids (Sritongchuay et al., 2014; Oleksy et al., 2015, 2017; van Toor et al., 2019), even though $89 \%$ of pteropodid species are tolerant of anthropogenic disturbance (IUCN, 2020).

The final major research gap is our limited understanding of how pteropodids respond to disturbances and threats, and the impacts these have on ecological roles. Disturbance and fragmentation alter pathways used by Neotropical bats (Meyer et al., 2016; Ferreira et al., 2017; Regolin et al., 2020) but is largely unstudied in pteropodids, even though 
it has consequences for resources used, pollination success, and seed deposition (McConkey and O'Farrill, 2016). Although pteropodids frequently feed on cultivated fruits and flowers, this is influenced by the quality of the native habitat (Krivek et al., 2020) and food abundance (Luskin, 2010), as many pteropodids appear to prefer wild fruits to cultivated ones (Korine et al., 1999; Nelson et al., 2000a; Andrianaivoarivelo et al., 2012). A more in-depth understanding of resource selection can improve our understanding of pteropodid-plant interactions and conflict with humans. Finally, population abundance has been shown to influence seed dispersal capacity for some Pteropus species (McConkey and Drake, 2006), and testing for this in more species, as well as how it impacts pollination, is required.

More open, equitable collaborations and data-sharing (e.g., the Bat Eco-Interactions Database ${ }^{1}$ ) among researchers and other professionals working on pteropodids would enable a more comprehensive documentation of the benefits pteropodids bring to ecosystems and humans. Such collaborations could be used to establish standardised protocols for documenting bat-plant interactions, and to develop training opportunities particularly for Global South researchers. Finally, the translation of research findings into a format accessible to the general public through popular science communication channels is particularly essential for overcoming negative public perceptions of bats, especially in places where awareness and appreciation of bats remains low.

\section{CONCLUSION}

Pteropodid bats play vital roles in seed dispersal and pollination, and are implicated as double mutualists for a diverse range of plant taxa. Island species are especially important for ecosystem functioning, but continental species have rarely been studied at a community level despite having the capacity for moving large numbers of seeds over the longest distances recorded for any animal. Well over half the world's pteropodid species remain unstudied in terms of their ecological roles, and many may experience multiple threats in various dimensions and scales. Even species that have been studied remain severely understudied in many aspects, often limited to just one study or single aspect. There is also a need to move away from species-driven research, especially research efforts and funding that focus solely on species diversity or endemism, and instead conduct research highlighting the importance of pteropodidplant interactions at a landscape level, and their importance for healthy ecosystem functioning, even when common or less threatened species are involved.

We hope the results and findings highlighted by this review will encourage more studies on pteropodid-plant interactions to bolster the knowledge necessary for understanding the conservation values associated with this important animal group. We urge more efforts to be directed towards areas where pteropodid-plant interactions are poorly understood or explored. A comprehensive understanding of pteropodid ecological roles and their implications for human well-being is necessary to

${ }^{1}$ https://batbase.org/ initiate effective conservation actions for an animal group that remains one of the least charismatic, and is consistently overlooked in research and conservation efforts.

\section{AUTHOR CONTRIBUTIONS}

SA, KM, KT, TS, TM, and PR contributed to the conception and design of the study. SA, KM, KT, M-RL, CN-D, VC-L, and $\mathrm{PR}$ performed the literature search and/or organised the database. SA, KM, KT, TS, M-RL, JY, and CN-D produced the figures and/or tables. SA wrote the first draft of the manuscript. SA, KM, KT, JY, TM, CN-D, and PR wrote sections of the manuscript. All authors reviewed and/or analysed the literature and contributed to manuscript revision, read, and approved the submitted version.

\section{FUNDING}

This research was made possible thanks to funding provided by the Embassy of France in Kuala Lumpur, Muséum National d'Histoire Naturelle, University of Nottingham Malaysia Campus, the Rufford Foundation (grants 17325-1, 25376-2, and 29639-B), Bat Conservation International, the University of Southampton, Rainforest Trust, The Habitat Foundation, the United States Fish and Wildlife Service (USFWS; grant F17AP00829), and numerous anonymous donors. This publication was made possible thanks to funding from the University of Exeter to cover the Article Processing Charge.

\section{ACKNOWLEDGMENTS}

We are deeply grateful to the Southeast Asian Bat Conservation Research Unit (SEABCRU; USA NSF Award \#1051363) for bringing the authors together, and the Philippines Biodiversity Conservation Fund (PBCF), Mabuwaya Foundation, Prince of Songkla University and the Secretariat of the 18th International Bat Research Conference (IBRC, 2019) for helping to facilitate further meetings and discussions. We are indebted to Reuben Clements for assisting with the literature search and analyses. We would also like to thank Khatijah Haji Hussin, Sara Bumrungsri, Tigga Kingston, Ahimsa Campos-Arceiz, PierreMichel Forget, Lisa Marie Paguntalan, Marcus Chua, and Tom Hughes for contributing input, advice, or information. We gratefully acknowledge Ricardo Rocha and Merlin Tuttle for providing constructive feedback to help improve the manuscript. We dedicate this manuscript to the memory of Greg C. Richards and Lim Boo Liat.

\section{SUPPLEMENTARY MATERIAL}

The Supplementary Material for this article can be found online at: https://www.frontiersin.org/articles/10.3389/fevo.2021. 641411/full\#supplementary-material 
Supplementary Information 1 | Methods and workflow for literature review.

Supplementary Information 2 | Pteropodid-Plant Interactions Database (1985-2020).

Supplementary Information $\mathbf{3}$ | Regional summaries of research on pteropodid-plant interactions during 1985-2020.

Supplementary Information 4 | Feeding signs of Pteropus bats on fruit.

\section{REFERENCES}

Abedi-Lartey, M. (2016). Quantifying the Ecological Impact of the Straw-Coloured Fruit Bat (Eidolon helvum) in West Africa. Ph. D. Thesis, Universität Konstanz, Baden-Württemberg.

Acharya, K. K., Roy, A., and Krishna, A. (1998). Relative role of olfactory cues and certain non-olfactory factors in foraging of fruit-eating bats. Behav. Processes 44, 59-64. doi: 10.1016/S0376-6357(98)00028-X

Acharya, P. R., Racey, P. A., Sotthibandhu, S., and Bumrungsri, S. (2015). Feeding behaviour of the dawn bat (Eonycteris spelaea) promotes cross pollination of economically important plants in Southeast Asia. J. Pollinat. Ecol. 15, 44-50. doi: 10.26786/1920-760320155

Agoramoorthy, G., and Hsu, M. J. (2005). Population size, feeding, forearm length and body weight of a less known Indian fruit bat, Latidens salimalii. Curr. Sci. 88, 354-356.

Anderson, J. T., Nuttle, T., Saldaña Rojas, J. S., Pendergast, T. H., and Flecker, A. S. (2011). Extremely long-distance seed dispersal by an overfished Amazonian frugivore. Proc. R. Soc. B Biol. Sci. 278, 3329-3335. doi: 10.1098/rspb.2011.0155

Andrianaivoarivelo, R. A., Jenkins, R. K. B., Petit, E. J., Ramilijaona, O., Razafindrakoto, N., and Racey, P. A. (2012). Rousettus madagascariensis (Chiroptera: Pteropodidae) shows a preference for native and commercially unimportant fruits. Endanger. Species Res. 19, 19-27. doi: 10.3354/esr0 0441

Andrianaivoarivelo, R. A., Ramilijaona, O. R., Racey, P. A., Razafindrakoto, N., and Jenkins, R. K. B. (2011). Feeding ecology, habitat use and reproduction of Rousettus madagascariensis Grandidier, 1928 (Chiroptera: Pteropodidae) in eastern Madagascar. Mammalia 75, 69-78. doi: 10.1515/mamm.2010.071

Aziz, S. A., Clements, G. R., Giam, X., Forget, P.-M., and Campos-Arceiz, A. (2017a). Coexistence and conflict between the island flying fox (Pteropus hypomelanus) and humans on Tioman Island, Peninsular Malaysia. Hum. Ecol. 45, 377-389. doi: 10.1007/s10745-017-9905-6

Aziz, S. A., Clements, G. R., McConkey, K. R., Sritongchuay, T., Pathil, S., Abu Yazid, M. N. H., et al. (2017c). Pollination by the locally endangered island flying fox (Pteropus hypomelanus) enhances fruit production of the economically important durian (Durio zibethinus). Ecol. Evol. 7, 8670-8684. doi: 10.1002/ ece 3.3213

Aziz, S. A., Clements, G. R., Peng, L. Y., Campos-Arceiz, A., McConkey, K. R., Forget, P.-M., et al. (2017b). Elucidating the diet of the island flying fox (Pteropus hypomelanus) in Peninsular Malaysia through Illumina NextGeneration Sequencing. PeerJ 5, e3176. doi: 10.7717/peerj.3176

Aziz, S. A., Olival, K. J., Bumrungsri, S., Richards, G. C., and Racey, P. A. (2016). "The conflict between pteropodid bats and fruit growers: species, legislation and mitigation," in Bats in the Anthropocene: Conservation of Bats in a Changing World, eds C. C. Voigt and T. Kingston (Cham: Springer International Publishing), 377-426. doi: 10.1007/978-3-319-25220-9_13

Bacles, C. F. E., Brooks, J., Lee, D. J., Schenk, P. M., Lowe, A. J., and Kremer, A. (2009). Reproductive biology of Corymbia citriodora subsp. variegata and effective pollination across its native range in Queensland, Australia. South. For. J. For. Sci. 71, 125-132. doi: 10.2989/SF.2009.71.2.7.822

Baker, D. J., Garnett, S. T., O’Connor, J., Ehmke, G., Clarke, R. H., Woinarski, J. C. Z., et al. (2018). Conserving the abundance of nonthreatened species. Conserv. Biol. 33, 319-328. doi: 10.1111/cobi.13197

Bates, P., Francis, C., Gumal, M., Bumrungsri, S., Walston, J., Heaney, L., et al. (2008). Pteropus vampyrus. The IUCN Red List of Threatened Species. Version 2020-3. Available online at: https://www.iucnredlist.org/en (accessed December $11,2020)$
Supplementary Information 5 | Foraging distances of pteropodids.

Supplementary Information $\mathbf{6}$ | Seed dispersal distances of pteropodids.

Supplementary Information 7 | Threats to pteropodid species as assessed by the IUCN (2020).

Supplementary Information 8 | IUCN Red-Listed pteropodid species with corresponding numbers of species-specific studies documenting aspects of bat-plant interactions during 1985-2020.

Bauer, S., and Hoye, B. J. (2014). Migratory animals couple biodiversity and ecosystem functioning worldwide. Science 344:1242552. doi: 10.1126/science. 1242552

Baum, D. A. (1995). The comparative pollination and floral biology of baobabs (Adansonia-Bombacaceae). Ann. Mol. Bot. Gard. 82, 322-348. doi: 10.2307/ 2399883

Bhat, H. R. (1994). Observations on the food and feeding behaviour of Cynopterus sphinx Vahl (Chiroptera, Pteropodidae) at Pune, India. Mammalia 58, 363-370. doi: 10.1515/mamm.1994.58.3.363

Birt, P. (2004). Mutualistic Interactions Between the Nectar-feeding Little Red Flying-Fox Pteropus scapulatus (Chiroptera: Pteropodidae) and Flowering Eucalypts (Myrtaceae): Habitat Utilisation and Pollination. Ph. D. Thesis, The University of Queensland, Brisbane, QLD.

Bittel, J. (2020). Experts Urge People All Over the World to Stop Killing Bats out of Fears of Coronavirus. NRDC. Available online at: https://www.nrdc.org/stories/ experts-urge-people-all-over-world-stop-killing-bats-out-fears-coronavirus (accessed November 5, 2020)

Boissier, O., Feer, F., Henry, P.-Y., and Forget, P.-M. (2020). Modifications of the rain forest frugivore community are associated with reduced seed removal at the community level. Ecol. Appl. 30:e02086. doi: 10.1002/eap.2086

Bollen, A., and van Elsacker, L. (2002). Feeding ecology of Pteropus rufus (Pteropodidae) in the littoral forest of Sainte Luce, SE Madagascar. Acta Chiropt. 4, 33-47. doi: 10.3161/001.004.0105

Bollen, A., Elsacker, L. V., and Ganzhorn, J. U. (2004). Relations between fruits and disperser assemblages in a Malagasy littoral forest: a community-level approach. J. Trop. Ecol. 20, 599-612. doi: 10.1017/S0266467404001853

Boulter, S. L., Kitching, R. L., Howlett, B. G., and Goodall, K. (2005). Any which way will do - the pollination biology of a northern Australian rainforest canopy tree (Syzygium sayeri; Myrtaceae). Bot. J. Linn. Soc. 149, 69-84. doi: 10.1111/j. 1095-8339.2005.00430.x

Bumrungsri, S., Harbit, A., Benzie, C., Carmouche, K., Sridith, K., and Racey, P. A. (2008). The pollination ecology of two species of Parkia (Mimosaceae) in southern Thailand. J. Trop. Ecol. 24, 467-475. doi: 10.1017/S0266467408005191

Bumrungsri, S., Sripaoraya, E., Chongsiri, T., Sridith, K., and Racey, P. A. (2009). The pollination ecology of durian (Durio zibethinus, Bombacaceae) in southern Thailand. J. Trop. Ecol. 25, 85-92. doi: 10.1017/S0266467408005531

Cain, M. L., Milligan, B. G., and Strand, A. E. (2000). Long-distance seed dispersal in plant populations. Am. J. Bot. 87, 1217-1227. doi: 10.2307/2656714

Campos-Arceiz, A., and Blake, S. (2011). Megagardeners of the forest - the role of elephants in seed dispersal. Acta Oecol. 37, 542-553. doi: 10.1016/j.actao.2011. 01.014

Castillo-Figueroa, D. (2020). Why bats matters: a critical assessment of batmediated ecological processes in the Neotropics. Eur. J. Ecol. 6, 77-101. doi: 10.17161/eurojecol.v6i1.13824

Chaiyarat, R., Boonma, W., and Koedrith, P. (2019). The role of pteropodid bats in pollination of durian (Durio zibethinus) in managed orchards in suburban habitat of Thailand. Urban Ecosyst. 23, 97-106. doi: 10.1007/s11252-01900919-w

Chaiyes, A., Duengkae, P., Wacharapluesadee, S., Pongpattananurak, N., Olival, K. J., and Hemachudha, T. (2017). Assessing the distribution, roosting site characteristics, and population of Pteropus lylei in Thailand. Raffles Bull. Zool. $65,670-680$.

Chan, A. A. Q., Aziz, S. A., Clare, E. L., and Coleman, J. L. (2020). Diet, ecological role and potential ecosystem services of the fruit bat, Cynopterus brachyotis, in a tropical city. Urban Ecosyst. doi: 10.1007/s11252-020-01034-x [Epub ahead of print]. 
Chen, S.-F., Shen, T.-J., Lee, H.-C., Wu, H.-W., Zeng, W.-T., Lu, D.-J., et al. (2017). Preference of an insular flying fox for seed figs enhances seed dispersal of a dioecious species. Biotropica 49, 511-520. doi: 10.1111/btp.12449

Clements, R., Sodhi, N. S., Schilthuizen, M., and Ng, P. K. L. (2006). Limestone Karsts of Southeast Asia: imperiled arks of biodiversity. BioScience 56, 733-742.

Clulow, S., and Blundell, A. T. (2011). Deliberate insectivory by the fruit bat Pteropus poliocephalus by Aerial Hunting. Acta Chiropt. 13, 201-205. doi: 10. 3161/150811011X578750

Corlett, R. T. (2005). Interactions between birds, fruit bats and exotic plants in urban Hong Kong, South China. Urban Ecosyst. 8, 275-283. doi: 10.1007/ s11252-005-3260-x

Corlett, R. T. (2006). Figs (Ficus, Moraceae) in urban Hong Kong, south China. Biotropica 38, 116-121. doi: 10.1111/j.1744-7429.2006.00109.x

Courts, S. E. (1998). Dietary strategies of old world fruit bats (Megachiroptera, Pteropodidae): how do they obtain sufficient protein? Mammal Rev. 28, 185194. doi: 10.1046/j.1365-2907.1998.00033.x

Cox, P. A., Banack, S. A., and Murch, S. J. (2003). Biomagnification of cyanobacterial neurotoxins and neurodegenerative disease among the Chamorro people of Guam. Proc. Natl. Acad. Sci. U.S.A. 100, 13380-13383. doi: $10.1073 /$ pnas. 2235808100

Cox, P. A., Elmqvist, T., Pierson, E. D., and Rainey, W. E. (1991). Flying foxes as strong interactors in south Pacific island ecosystems: a conservation hypothesis. Conserv. Biol. 5, 448-454. doi: 10.1111/j.1523-1739.1991.tb00351.x

Craig, T., Trail, P., and Morrell, T. E. (1994). The decline of fruit bats in American Samoa due to hurricanes and overhunting. Biol. Conserv. 69, 261-266. doi: 10.1016/0006-3207(94)90425-1

Crome, F. H. J., and Irvine, A. K. (1986). "Two bob each way": the pollination and breeding system of the Australian rain forest tree Syzygium cormiflorum (Myrtaceae). Biotropica 18, 115-125. doi: 10.2307/2388754

Daly, N. (2020). Flying Foxes are Dying en Masse in Australia's Extreme Heat. National Geographic. Available online at: https://www.nationalgeographic.com/ animals/2020/01/flying-foxes-are-dying-en-masse-in-australias-extremeheat/ (accessed November 28, 2020)

Deshpande, K., and Kelkar, N. (2015). How do fruit bat seed shadows benefit agroforestry? Insights from local perceptions in Kerala, India. Biotropica 47, 654-659. doi: 10.1111/btp.12275

Djossa, B. A., Fahr, J., Kalko, E. K. V., and Sinsin, B. A. (2008). Fruit selection and effects of seed handling by flying foxes on germination rates of shea trees, a key resource in northern Benin, West Africa. Ecotropica 14, 37-48.

Djossa, B. A., Toni, H. C., Adekanmbi, I. D., Tognon, F. K., and Sinsin, B. A. (2015). Do flying foxes limit flower abortion in African baobab (Adansonia digitata)? Case study in Benin, West Africa. Fruits 70, 281-287. doi: 10.1051/ fruits/2015029

Dorrestein, A., Todd, C. M., Westcott, D. A., Martin, J. M., and Welbergen, J. A. (2019). Impacts of an invasive ant species on roosting behavior of an island endemic flying-fox. Biotropica 51, 75-83. doi: 10.1111/btp. 12620

Duron, Q., Garcia-Iriarte, O., Brescia, F., and Vidal, E. (2017). Comparative effects of native frugivores and introduced rodents on seed germination in NewCaledonian rainforest plants. Biol. Invasions 19, 351-363. doi: 10.1007/s10530016-1284-1

Eby, P. (1998). An analysis of diet specialization in frugivorous Pteropus poliocephalus (Megachiroptera) in Australian subtropical rainforest. Aust. J. Ecol. 23, 443-456. doi: 10.1111/j.1442-9993.1998.tb00752.x

Elmqvist, T., Cox, P. A., Rainey, W. E., and Pierson, E. D. (1992). Restricted pollination on oceanic islands: pollination of Ceiba pentandra by flying foxes in Samoa. Biotropica 24, 15-23. doi: 10.2307/2388469

Entwistle, A., and Corp, N. (1997). The diet of Pteropus voeltzkowi, an endangered fruit bat endemic to Pemba Island, Tanzania. Afr. J. Ecol. 35, 351-360. doi: 10.1111/j.1365-2028.1997.092-8900092.x

Epstein, J. H., Olival, K. J., Pulliam, J. R. C., Smith, C., Westrum, J., Hughes, T., et al. (2009). Pteropus vampyrus, a hunted migratory species with a multinational home-range and a need for regional management. J. Appl. Ecol. 46, 991-1002. doi: 10.1111/j.1365-2664.2009.01699.x

Erancheri, P., Sunojkumar, P., and Dilsha Das, M. (2013). Bat pollination in medicinally important Cochlospermum religiosum. Ann. Plant Sci. 2, 292-295.

Esselstyn, J. A., Amar, A., and Janeke, D. (2006). Impact of post-typhoon hunting on mariana fruit bats (Pteropus mariannus). Pac. Sci. 60, 531-539. doi: 10.1353/ psc. 2006.0027
Ferreira, D. F., Rocha, R., López-Baucells, A., Farneda, F. Z., Carreiras, J. M. B., Palmeirim, J. M., et al. (2017). Season-modulated responses of Neotropical bats to forest fragmentation. Ecol. Evol. 7, 4059-4071. doi: 10.1002/ece3. 3005

Fleming, T. H. (2019). “Bat migration,” in Encyclopedia of Animal Behavior, ed. J. C. Choe (Cambridge, MA: Acadamic Press), 605-610. doi: 10.1016/B978-012-809633-8.20764-4

Fleming, T. H., Breitwisch, R., and Whitesides, G. H. (1987). Patterns of tropical vertebrate frugivore diversity. Annu. Rev. Ecol. Syst. 18, 91-109. doi: 10.1146/ annurev.es.18.110187.000515

Fleming, T. H., and Racey, P. A. (2009). Island Bats: Evolution, Ecology, and Conservation. Chicago, IL: University of Chicago Press.

Florens, F. B. V., and Baider, C. (2019). Mass-culling of a threatened island flying fox species failed to increase fruit growers' profits and revealed gaps to be addressed for effective conservation. J. Nat. Conserv. 47, 58-64. doi: 10.1016/ j.jnc.2018.11.008

Florens, F. B. V., Baider, C., Marday, V., Martin, G. M. N., Zmanay, Z., Oleksy, R. Z., et al. (2017). Disproportionately large ecological role of a recently massculled flying fox in native forests of an oceanic island. J. Nat. Conserv. 40, 85-93. doi: 10.1016/j.jnc.2017.10.002

Francis, C. M., Rosell-Ambal, G., Tabaranza, B. R., Carino, A., Helgen, K. M., Molur, S., et al. (2008). Eonycteris spelaea. IUCN Red List Threat. Species 2008 ET7787A12850087. Cambridge: IUCN Red List, doi: 10.2305/IUCN.UK.2008. RLTS.T7787A12850087.en

Frick, W. F., Kingston, T., and Flanders, J. (2019). A review of the major threats and challenges to global bat conservation. Ann. N. Y. Acad. Sci. 1469, 5-25. doi: $10.1111 /$ nyas. 14045

Friess, D. A., Yando, E. S., Alemu, J. B. I, Wong, L.-W., Soto, S. D., and Bhatia, N. (2020). "Ecosystem services and disservices of mangrove forests and salt marshes," in Oceanography and Marine Biology: An Annual Review, Vol. 58, eds S. J. Hawkins, A. L. Allcock, A. E. Bates, A. J. Evans, L. B. Firth, C. D. McQuaid, et al. (Oxford: Taylor \& Francis), 107-142.

Fujita, M. S., and Tuttle, M. D. (1991). Flying foxes (Chiroptera: Pteropodidae): threatened animals of key ecological and economic importance. Conserv. Biol. 5, 455-463. doi: 10.1111/j.1523-1739.1991.tb00352.x

Fuster, F., Kaiser-Bunbury, C., Olesen, J. M., and Traveset, A. (2019). Global patterns of the double mutualism phenomenon. Ecography 42, 826-835. doi: 10.1111/ecog.04008

Gonzales, R. S., Ingle, N. R., Lagunzad, D. A., and Nakashizuka, T. (2009). Seed dispersal by birds and bats in lowland philippine forest successional area. Biotropica 41, 452-458. doi: 10.1111/j.1744-7429.2009.00501.x

Goveas, S. W., Miranda, E. C., Seena, S., and Sridhar, K. R. (2006). Observations on guano and bolus of Indian flying fox, Pteropus giganteus. Curr. Sci. 90, $160-162$.

Grant, G. S., Craig, P., and Trail, P. W. (1997). Cyclone-induced shift in foraging behavior in flying foxes in American Samoa. Biotropica 29, 224-228. doi: 10. 1111/j.1744-7429.1997.tb00027.x

Groffen, J., Rethus, G., and Pettigrew, J. (2016). Promiscuous pollination of Australia's baobab, the boab, Adansonia gregorii. Aust. J. Bot. 64, 678-686. doi: 10.1071/BT16049

Gumal, M. T. (2001). Ecology and Conservation of a Fruit Bat in Sarawak, Malaysia. $\mathrm{Ph}$. D. Dissertation, University of Cambridge, Cambridge.

Harten, L., Katz, A., Goldshtein, A., Handel, M., and Yovel, Y. (2020). The ontogeny of a mammalian cognitive map in the real world. Science 369, 194-197. doi: 10.1126/science.aay3354

Helbig-Bonitz, M., Rutten, G., and Kalko, E. K. V. (2013). Fruit bats can disperse figs over different land-use types on Mount Kilimanjaro, Tanzania. Afr. J. Ecol. 52, 122-125. doi: 10.1111/aje.12090

Hodgkison, R., Ayasse, M., Häberlein, C., Schulz, S., Zubaid, A., Mustapha, W. A. W., et al. (2013). Fruit bats and bat fruits: the evolution of fruit scent in relation to the foraging behaviour of bats in the New and Old World tropics. Funct. Ecol. 27, 1075-1084. doi: 10.1111/1365-2435.12101

Hodgkison, R., Ayasse, M., Kalko, E. K. V., Häberlein, C., Schulz, S., Mustapha, W. A. W., et al. (2007). Chemical ecology of fruit bat foraging behavior in relation to the fruit odors of two species of paleotropical bat-dispersed figs (Ficus hispida and Ficus scortechinii). J. Chem. Ecol. 33, 2097-2110. doi: 10.1007/ s10886-007-9367-1

Hodgkison, R., Balding, S. T., Zubaid, A., and Kunz, T. H. (2003). Fruit bats (Chiroptera: Pteropodidae) as seed dispersers and pollinators in a lowland 
Malaysian rain forest. Biotropica 35, 491-502. doi: 10.1111/j.1744-7429.2003. tb00606.x

Hodgkison, R., Balding, S. T., Zubaid, A., and Kunz, T. H. (2004). Temporal variation in the relative abundance of fruit bats (Megachiroptera: Pteropodidae) in relation to the availability of food in a lowland Malaysian rain forest. Biotropica 36, 522-533. doi: 10.1646/1593

Ingle, N. R. (2003). Seed dispersal by wind, birds, and bats between Philippine montane rainforest and successional vegetation. Oecologia 134, 251-261. doi: 10.1007/s00442-002-1081-7

Inkscape Project (2021). Inkscape. Available online at: https://inkscape.org (accessed May 1, 2020).

Itino, T., Kato, M., and Hotta, M. (1991). Pollination ecology of the two wild bananas, Musa acuminata subsp. halabanensis and M. salaccensis: Chiropterophily and ornithophily. Biotropica 23, 151-158. doi: 10.2307/ 2388300

IUCN (2020). The IUCN Red List of Threatened Species. Version 2020-2. Available online at: https://www.iucnredlist.org/en (accessed March 1, 2021).

Izhaki, I., Korine, C., and Arad, Z. (1995). The effect of bat (Rousettus aegyptiacus) dispersal on seed germination in eastern Mediterranean habitats. Oecologia 101, 335-342. doi: 10.1007/BF00328820

Jenkins, R. K. B., and Racey, P. A. (2008). Bats as bushmeat in Madagascar. Madag. Conserv. Dev. 3, 22-30. doi: 10.4314/mcd.v3i1.44132

Jones, G., Jacobs, D. S., Kunz, T. H., Willig, M. R., and Racey, P. A. (2009). Carpe noctem: the importance of bats as bioindicators. Endanger. Species Res. 8, 93-115. doi: 10.3354/esr00182

Jordaan, L. A., Johnson, S. D., and Downs, C. T. (2012). Wahlberg's epauletted fruit bat (Epomophorus wahlbergi) as a potential dispersal agent for fleshy-fruited invasive alien plants: effects of handling behaviour on seed germination. Biol. Invasions 14, 959-968. doi: 10.1007/s10530-011-0131-7

Kingston, T. (2016). "Cute, creepy, or crispy-How values, attitudes, and norms shape human behavior toward bats," in Bats in the Anthropocene: Conservation of Bats in a Changing World, eds C. C. Voigt and T. Kingston (Cham: Springer International Publishing), 571-595. doi: 10.1007/978-3-319-25220-9_18

Kitamura, S. (2011). Frugivory and seed dispersal by hornbills (Bucerotidae) in tropical forests. Acta Oecol. 37, 531-541. doi: 10.1016/j.actao.2011.01.015

Kobayashi, S., Gale, S. W., Denda, T., and Izawa, M. (2020). Rat- and batpollination of Mucuna championii (Fabaceae) in Hong Kong. Plant Species Biol. 36, 84-93. doi: 10.1111/1442-1984.12298

Korine, C., Izhaki, I., and Arad, Z. (1998). Comparison of fruit syndromes between the Egyptian fruit-bat (Rousettus aegyptiacus) and birds in East Mediterranean habitats. Acta Oecol. 19, 147-153. doi: 10.1016/S1146-609X(98)80018-0

Korine, C., Izhaki, I., and Arad, Z. (1999). Is the Egyptian fruit-bat Rousettus aegyptiacus a pest in Israel? An analysis of the bat's diet and implications for its conservation. Biol. Conserv. 88, 301-306. doi: 10.1016/S0006-3207(98)0 0126-8

Krivek, G., Florens, F. B. V., Baider, C., Seegobin, V. O., and Haugaasen, T. (2020). Invasive alien plant control improves foraging habitat quality of a threatened island flying fox. J. Nat. Conserv. 54:125805. doi: 10.1016/j.jnc.2020.12 5805

Kung, N. Y., Field, H. E., McLaughlin, A., Edson, D., and Taylor, M. (2015). Flying-foxes in the Australian urban environment-community attitudes and opinions. One Health 1, 24-30. doi: 10.1016/j.onehlt.2015.07.002

Kunz, T. H., Braun de Torrez, E., Bauer, D., Lobova, T., and Fleming, T. H. (2011). Ecosystem services provided by bats. Ann. N. Y. Acad. Sci. 1223, 1-38. doi: 10.1111/j.1749-6632.2011.06004.x

Kunz, T. H., and Diaz, C. A. (1995). Folivory in fruit-eating bats, with new evidence from Artibeus jamaicensis (Chiroptera: Phyllostomidae). Biotropica 27, 106-120. doi: 10.2307/2388908

Kunz, T. H., and Pierson, E. D. (1994). "Bats of the world: an introduction," in Walker's Bats of the World, eds R. M. Nowak and E. P. Walker (Baltimore, MD: The John Hopkins University Press), 1-46.

Lacher, T. E., Davidson, A. D., Fleming, T. H., Gómez-Ruiz, E. P., McCracken, G. F., Owen-Smith, N., et al. (2019). The functional roles of mammals in ecosystems. J. Mammal. 100, 942-964. doi: 10.1093/jmammal/gyy183

Laman, T. G. (1995). The ecology of strangler fig seedling establishment. Selbyana $16,223-229$.

Larsen, E., Beck, M., Hartnell, E., and Creenaune, M. (2002). "Neighbours of Kuring-gai flying-fox reserve: community attitudes survey 2001," in Managing the
Grey-headed Flying-fox as a Threatened Species in New South Wales, eds P. Eby and D. Lunney (Mosman, NSW: Royal Zoological Society of New South Wales), 225-239. doi: 10.7882/FS.2002.055

Lassen, K. M., Ræbild, A., Hansen, H., Brødsgaard, C. J., and Eriksen, E. N. (2012). Bats and bees are pollinating Parkia biglobosa in The Gambia. Agrofor. Syst. 85, 465-475. doi: 10.1007/s10457-011-9409-0

Laurindo, R., de, S., Vizentin-Bugoni, J., Tavares, D. C., Mancini, M. C. S., Mello, R., et al. (2020). Drivers of bat roles in Neotropical seed dispersal networks: abundance is more important than functional traits. Oecologia 193, 189-198. doi: 10.1007/s00442-020-04662-4

Lavery, T. H., and Fasi, J. (2019). Buying through your teeth: traditional currency and conservation of flying foxes Pteropus spp. in Solomon Islands. Oryx 53, 505-512. doi: 10.1017/S0030605317001004

Lavery, T. H., Leary, T. N., Shaw, C., Tahi, M., Posala, C., and Pierce, R. (2020). Ecology and conservation of bats in Temotu Province, Solomon Islands and Torba Province, Vanuatu. Pac. Conserv. Biol. 27, 27-38. doi: 10.1071/PC20035

Law, B. S., and Lean, M. (1999). Common blossom bats (Syconycteris australis) as pollinators in fragmented Australian tropical rainforest. Biol. Conserv. 91, 201-212. doi: 10.1016/S0006-3207(99)00078-6

Lee, S. S., Yaakob, N. S., Boon, K. S., and Chua, L. S. L. (2002). The role of selected animals in pollination and dispersal of trees in the forest: implications for conservation and management. J. Trop. For. Sci. 14, 234-263.

Lewanzik, D., and Voigt, C. C. (2014). Artificial light puts ecosystem services of frugivorous bats at risk. J. Appl. Ecol. 51, 388-394. doi: 10.1111/1365-2664. 12206

Li, L., Chi, H., Liu, H., Xia, Y., Irwin, D. M., Zhang, S., et al. (2018). Retention and losses of ultraviolet-sensitive visual pigments in bats. Sci. Rep. 8:11933. doi: 10.1038/s41598-018-29646-6

Lim, V.-C., Clare, E. L., Littlefair, J. E., Ramli, R., Bhassu, S., and Wilson, J.-J. (2018). Impact of urbanisation and agriculture on the diet of fruit bats. Urban Ecosyst. 21, 61-70. doi: 10.1007/s11252-017-0700-3

Liu, A.-Z., Li, D.-Z., Wang, H., and Kress, W. J. (2002). Ornithophilous and chiropterophilous pollination in Musa itinerans (Musaceae), a pioneer species in tropical rain forests of Yunnan, Southwestern China. Biotropica 34, 254-260. doi: 10.1111/j.1744-7429.2002.tb00536.x

Loh, I. H., Chong, J. L., and Baird, M. H. (2018). The conservation of coral reefs through mangrove management. Biodiversity 19, 95-100. doi: 10.1080/ 14888386.2018.1473168

Long, E., and Racey, P. A. (2007). An exotic plantation crop as a keystone resource for an endemic megachiropteran, Pteropus rufus, in Madagascar. J. Trop. Ecol. 23, 397-407. doi: 10.1017/S0266467407004178

López-Baucells, A., Rocha, R., and Fernández-Llamazares, Á (2018). When bats go viral: negative framings in virological research imperil bat conservation. Mammal Rev. 48, 62-66. doi: 10.1111/mam.12110

Lu, M., Wang, X., Ye, H., Wang, H., Qiu, S., Zhang, H., et al. (2021). Does public fear that bats spread COVID-19 jeopardize bat conservation? Biol. Conserv. 254, 108952. doi: 10.016/j.biocon.2021.108952

Luft, S., Curio, E., and Tacud, B. (2003). The use of olfaction in the foraging behaviour of the golden-mantled flying fox, Pteropus pumilus, and the greater musky fruit bat, Ptenochirus jagori (Megachiroptera: Pteropodidae). Naturwissenschaften 90, 84-87. doi: 10.1007/s00114-002-0393-0

Lunney, D., and Moon, C. (2011). "Blind to bats: traditional prejudices and today's bad press render bats invisible to public consciousness," in The Biology and Conservation of Australasian Bats, eds B. S. Law, P. Eby, D. Lunney, and L. Lumsden (Mosman, NSW: Royal Zoological Society of New South Wales), 44-63.

Luskin, M. S. (2010). Flying foxes prefer to forage in farmland in a tropical dry forest landscape mosaic in Fiji. Biotropica 42, 246-250. doi: 10.1111/j.17447429.2009.00577.x

Mahandran, V., Murugan, C. M., Marimuthu, G., and Nathan, P. T. (2018). Seed dispersal of a tropical deciduous Mahua tree, Madhuca latifolia (Sapotaceae) exhibiting bat-fruit syndrome by pteropodid bats. Glob. Ecol. Conserv. 14:e00396. doi: 10.1016/j.gecco.2018.e00396

Marshall, A. G. (1983). Bats, flowers and fruit: evolutionary relationships in the Old World. Biol. J. Linn. Soc. 20, 115-135. doi: 10.1111/j.1095-8312.1983.tb01593.x

Marshall, A. G. (1985). Old World phytophagous bats (Megachiroptera) and their food plants: a survey. Zool. J. Linn. Soc. 83, 351-369. doi: 10.1111/j.1096-3642. 1985.tb01181.x 
McConkey, K. R. (2018). Seed dispersal by primates in Asian habitats: from species, to communities, to conservation. Int. J. Primatol. 39, 466-492. doi: 10.1007/ s10764-017-0013-7

McConkey, K. R., and Drake, D. R. (2006). Flying foxes cease to function as seed dispersers long before they become rare. Ecology 87, 271-276. doi: 10.1890/050386

McConkey, K. R., and Drake, D. R. (2007). Indirect evidence that flying foxes track food resources among islands in a Pacific archipelago. Biotropica 39, 436-440. doi: $10.1111 / \mathrm{j} .1744-7429.2007 .00269 . \mathrm{x}$

McConkey, K. R., and Drake, D. R. (2015). Low redundancy in seed dispersal within an island frugivore community. AoB PLANTS 7:lv088. doi: 10.1093/ aobpla/plv088

McConkey, K. R., Drake, D. R., Franklin, J., and Tonga, F. (2004). Effects of Cyclone Waka on flying foxes (Pteropus tonganus) in the Vava'u Islands of Tonga. J. Trop. Ecol. 20, 555-561. doi: 10.1017/S0266467404001804

McConkey, K. R., and O'Farrill, G. (2016). Loss of seed dispersal before the loss of seed dispersers. Biol. Conserv. 201, 38-49. doi: 10.1016/j.biocon.2016. 06.024

Meng, L., Gao, X., Chen, J., and Martin, K. (2012). Spatial and temporal effects on seed dispersal and seed predation of Musa acuminata in southern Yunnan, China. Integr. Zool. 7, 30-40. doi: 10.1111/j.1749-4877.2011.00275.x

Meyer, C. F. J., Struebig, M. J., and Willig, M. R. (2016). "Responses of tropical bats to habitat fragmentation, logging, and deforestation," in Bats in the Anthropocene: Conservation of Bats in a Changing World, eds C. C. Voigt and T. Kingston (Cham: Springer International Publishing), 63-103. doi: 10.1007/ 978-3-319-25220-9_4

Mickleburgh, S. P., Hutson, A. M., and Racey, P. A. (1992). Old World Fruit Bats: An Action Plan for their Conservation. Gland: International Union for Conservation of Nature and Natural Resources.

Mildenstein, T., Tanshi, I., and Racey, P. A. (2016). "Exploitation of bats for bushmeat and medicine," in Bats in the Anthropocene: Conservation of Bats in a Changing World, eds C. C. Voigt and T. Kingston (Cham: Springer International Publishing), 325-375. doi: 10.1007/978-3-319-25220-9_12

Mildenstein, T. L. (2002). Habitat Selection of Large Flying Foxes Using Radio Telemetry: Targeting Conservation Efforts in Subic Bay, Philippines. M. Sc. Thesis, University of Montana, Missoula, MT.

Mildenstein, T. L. (2012). Conservation of Endangered Flying Foxes in the Philippines: Effects of Anthropogenic Disturbance and Research Methods for Community-Based Conservation. Ph. D. Dissertation, University of Montana, Missoula, MT.

Mildenstein, T. L. (2020). Pteropus mariannus species account and assessment. IUCN Red List Threat. Species. Cambridge: IUCN Red List.

Mildenstein, T. L., Stier, S. C., Nuevo-Diego, C. E., and Mills, L. S. (2005). Habitat selection of endangered and endemic large flying-foxes in Subic Bay, Philippines. Biol. Conserv. 126, 93-102. doi: 10.1016/j.biocon.2005.05.001

Momose, K., Yumoto, T., Nagamitsu, T., Kato, M., Nagamasu, H., Sakai, S., et al. (1998). Pollination biology in a lowland dipterocarp forest in Sarawak, Malaysia. I. Characteristics of the plant-pollinator community in a lowland dipterocarp forest. Am. J. Bot. 85, 1477-1501.

Moussy, C., Hosken, D. J., Mathews, F., Smith, G. C., Aegerter, J. N., and Bearhop, S. (2013). Migration and dispersal patterns of bats and their influence on genetic structure. Mammal Rev. 43, 183-195. doi: 10.1111/j.1365-2907.2012.00218.x

Mumby, P. J. (2006). Connectivity of reef fish between mangroves and coral reefs: algorithms for the design of marine reserves at seascape scales. Biol. Conserv. 128, 215-222. doi: 10.1016/j.biocon.2005.09.042

Nakamoto, A., Kinjo, K., and Izawa, M. (2009). The role of Orii's flying-fox (Pteropus dasymallus inopinatus) as a pollinator and a seed disperser on Okinawa-jima Island, the Ryukyu Archipelago, Japan. Ecol. Res. 24, 405-414. doi: 10.1007/s11284-008-0516-y

Nakamoto, A., Kinjo, K., and Izawa, M. (2015). Dietary plasticity in the Ryukyu Flying Fox on a subtropical island at the northern range limit of Pteropus. Acta Chiropt. 17, 105-117. doi: 10.3161/15081109ACC2015.17.1.009

Nathan, P. T., Karuppudurai, T., Raghuram, H., and Marimuthu, G. (2009). Bat foraging strategies and pollination of Madhuca latifolia (Sapotaceae) in southern India. Acta Chiropt. 11, 435-441.

Nathan, P. T., Raghuram, H., Elangovan, V., Karuppudurai, T., and Marimuthu, G. (2005). Bat pollination of kapok tree, Ceiba pentandra. Curr. Sci. 88, 1679-1681.
Nelson, S. L., Masters, D. V., Humphrey, S. R., and Kunz, T. H. (2005). Fruit choice and calcium block use by Tongan fruit bats in American Samoa. J. Mammal. 86, 1205-1209. doi: 10.1644/05-MAMM-A-004R1.1

Nelson, S. L., Miller, M. A., Heske, E. J., and Fahey, G. C. Jr. (2000b). Nutritional quality of leaves and unripe fruit consumed as famine foods by the flying foxes of Samoa. Pac. Sci. 54, 301-311.

Nelson, S. L., Miller, M. A., Heske, E. J., and Fahey, G. C. (2000a). Nutritional consequences of a change in diet from native to agricultural fruits for the Samoan fruit bat. Ecography 23, 393-401. doi: 10.1111/j.1600-0587.2000. tb00296.x

Nogueira, M. R., Monteiro, L. R., Peracchi, A. L., and de Araújo, A. F. B. (2005). Ecomorphological analysis of the masticatory apparatus in the seed-eating bats, genus Chiroderma (Chiroptera: Phyllostomidae). J. Zool. 266, 355-364. doi: 10.1017/S0952836905007053

Nogueira, M. R., and Peracchi, A. L. (2003). Fig-Seed Predation by 2 species of Chiroderma: discovery of a new feeding strategy in bats. J. Mammal. 84, 225-233.

Nor Zalipah, M., and Ahmad Fadhli, A. (2017). Experimental pollinator exclusion of Sonneratia alba suggests bats are more important pollinator agents than moths. J. Sustain. Sci. Manag. 2017, 16-23.

Nor Zalipah, M., Shahrul Anuar, M. S., and Jones, G. (2016). The potential significance of nectar-feeding bats as pollinators in mangrove habitats of Peninsular Malaysia. Biotropica 48, 425-428. doi: 10.1111/btp.12335

Nuevo Diego, C. E. (2018). Floral Characteristics and Pollination of Sonneratia spp. (Lythraceae) in Southern Thailand. M. Sc. Thesis, Prince of Songkla University, Hat Yai.

Nuevo Diego, C. E., Stewart, A. B., and Bumrungsri, S. (2019). Pollinators increase reproductive success of a self-compatible Mangrove, Sonneratia ovata, in Southern Thailand. Trop. Nat. Hist. 19, 88-102.

Nyhagen, D. F., Turnbull, S. D., Olesen, J. M., and Jones, C. G. (2005). An investigation into the role of the Mauritian flying fox, Pteropus niger, in forest regeneration. Biol. Conserv. 122, 491-497. doi: 10.1016/j.biocon.2004.08.012

Oedin, M., Brescia, F., Millon, A., Murphy, B. P., Palmas, P., Woinarski, J. C., et al. (2021). Cats Felis catus as a threat to bats worldwide: a review of the evidence. Mamm. Rev. doi: 10.1111/mam. 12240

Oleksy, R. Z., Ayady, C. L., Tataya, V., Jones, C., Froidevaux, J. S., Racey, P. A., et al. (2018). The impact of the endangered Mauritian flying fox Pteropus niger on commercial fruit farms and the efficacy of mitigation. Oryx 55, 114-121. doi: 10.1017/S0030605318001138

Oleksy, R. Z., Ayady, C. L., Tatayah, V., Jones, C., Howey, P. W., Froidevaux, J. S. P., et al. (2019). The movement ecology of the Mauritian flying fox (Pteropus niger): a long-term study using solar-powered GSM/GPS tags. Mov. Ecol. 7:12. doi: 10.1186/s40462-019-0156-6

Oleksy, R. Z., Giuggioli, L., McKetterick, T. J., Racey, P. A., and Jones, G. (2017). Flying foxes create extensive seed shadows and enhance germination success of pioneer plant species in deforested Madagascan landscapes. PLoS One 12:e0184023. doi: 10.1371/journal.pone.0184023

Oleksy, R. Z., Racey, P. A., and Jones, G. (2015). High-resolution GPS tracking reveals habitat selection and the potential for long-distance seed dispersal by Madagascan flying foxes Pteropus rufus. Glob. Ecol. Conserv. 3, 678-692. doi: 10.1016/j.gecco.2015.02.012

Olesen, J. M., Damgaard, C. F., Fuster, F., Heleno, R. H., Nogales, M., Rumeu, B., et al. (2018). Disclosing the double mutualist role of birds on Galápagos. Sci. Rep. 8:57. doi: 10.1038/s41598-017-17592-8

Ong, L. (2020). The Ecological Functions of Asian Elephants in the Sundaic Rainforest: Herbivory and Seed Dispersal. Ph. D. Thesis, University of Nottingham Malaysia Campus, Semenyih.

O'Shea, T. J., Cryan, P. M., Hayman, D. T. S., Plowright, R. K., and Streicker, D. G. (2016). Multiple mortality events in bats: a global review. Mammal Rev. 46, 175-190. doi: 10.1111/mam.12064

Osuri, A. M., Mendiratta, U., Naniwadekar, R., Varma, V., and Naeem, S. (2020). Hunting and forest modification have distinct defaunation impacts on tropical mammals and birds. Front. For. Glob. Change 2:87. doi: 10.3389/ffgc.2019. 00087

PERHILITAN (2017). Red List of Mammals for Peninsular Malaysia. Version 2.0. Kuala Lumpur: Department of Wildlife and National Parks Peninsular Malaysia (PERHILITAN). 
Pierson, E. D., and Rainey, W. E. (1992). "The biology of flying foxes of the genus Pteropus: a review," in Pacific Island Flying Foxes: Proceedings of an International Conservation Conference US Fish and Wildlife Service Biological Report, (Washington, DC).

Pierson, E. D., Elmqvist, T., Rainey, W. E., and Cox, P. A. (1996). Effects of tropical cyclonic storms on flying fox populations on the south Pacific islands of Samoa. Conserv. Biol. 10, 438-451. doi: 10.1046/j.1523-1739.1996.10020438.x

R Core Team (2021). R: A Language and Environment for Statistical Computing. Vienna: R Foundation for Statistical Computing.

Raghuram, H., Thangadurai, C., Gopukumar, N., Nathar, K., and Sripathi, K. (2009). The role of olfaction and vision in the foraging behaviour of an echolocating megachiropteran fruit bat, Rousettus leschenaulti (Pteropodidae). Mamm. Biol. 74, 9-14. doi: 10.1016/j.mambio.2008.02.008

Ratto, F., Simmons, B. I, Spake, R., Zamora-Gutierrez, V., MacDonald, M. A., Merriman, J. C., et al. (2018). Global importance of vertebrate pollinators for plant reproductive success: a meta-analysis. Front. Ecol. Environ. 16:82-90. doi: $10.1002 /$ fee. 1763

Redford, K., Berger, J., and Zack, S. (2013). Abundance as a conservation value. Oryx 47, 157-158.

Regolin, A. L., Muylaert, R. L., Crestani, A. C., Dáttilo, W., and Ribeiro, M. C. (2020). Seed dispersal by Neotropical bats in human-disturbed landscapes. Wildl. Res. 48, 1-6. doi: 10.1071/WR19138

Reinegger, R. D., Oleksy, R. Z., Bissessur, P., Naujeer, H. and Jones, G. (2021). First come, first served: fruit availability to keystone bat species is potentially reduced by invasive macaques. J. Mammal. doi: 10.1093/jmammal/gyaa182

Reuters (2019). Thousands of baby flying foxes starve after Australian bushfires. Canary Wharf: Reuters.

Richards, G. C. (1990). The spectacled flying fox, Pteropus conspicillatus, in north Queensland. 2. Diet, feeding ecology and seed dispersal. Aust. Mammal. 13, 25-31.

Richards, G. C. (1995). A review of ecological interactions of fruit bats in Australian ecosystems. Symp. Zool. Soc. Lond. 67, 79-96.

Richmond, J. Q., Banack, S. A., and Grant, G. S. (1998). Comparative analysis of wing morphology, flight behaviour, and habitat use in flying foxes (Genus: Pteropus). Aust. J. Zool. 46, 283-289. doi: 10.1071/zo97059

Richter, H. V., and Cumming, G. S. (2005). Food availability and annual migration of the straw-colored fruit bat (Eidolon helvum). J. Zool. 268, 35-44. doi: 10.1111/ j.1469-7998.2005.00020.x

Richter, H. V., and Cumming, G. S. (2008). First application of satellite telemetry to track African straw-coloured fruit bat migration. J. Zool. 275, 172-176. doi: $10.1111 / j .1469-7998.2008 .00425 . x$

Roberts, B. J., Catterall, C. P., Eby, P., and Kanowski, J. (2012). Long-distance and frequent movements of the flying-fox Pteropus poliocephalus: implications for management. PLoS One 7:e42532. doi: 10.1371/journal.pone.0042532

Rocha, R., Aziz, S. A., Brook, C. E., Carvalho, W. D., Cooper-Bohannon, R., Frick, W. F., et al. (2020). Bat conservation and zoonotic disease risk: a research agenda to prevent misguided persecution in the aftermath of COVID-19. Anim. Conserv. doi: 10.1111/acv.12636 [Epub ahead of print].

Rogers, H. S., Buhle, E. R., HilleRisLambers, J., Fricke, E. C., Miller, R. H., and Tewksbury, J. J. (2017). Effects of an invasive predator cascade to plants via mutualism disruption. Nat. Commun. 8:14557. doi: 10.1038/ncomms14557

Sales, L. P., Kissling, W. D., Galetti, M., Naimi, B., and Pires, M. M. (2021). Climate change reshapes the eco-evolutionary dynamics of a Neotropical seed dispersal system. Glob. Ecol. Biogeogr. doi: 10.1111/geb.13271 [Epub ahead of print].

Savidge, J. A. (1987). Extinction of an Island Forest Avifauna by an Introduced Snake. Ecology 68, 660-668. doi: 10.2307/1938471

Scanlon, A. T., Petit, S., Tuiwawa, M., and Naikatini, A. (2014). High similarity between a bat-serviced plant assemblage and that used by humans. Biol. Conserv. 174, 111-119. doi: 10.1016/j.biocon.2014.03.023

Scanlon, A. T., Petit, S., Tuiwawa, M., and Naikatini, A. (2018). Response of primary and secondary rainforest flowers and fruits to a cyclone, and implications for plant-servicing bats. Glob. Change Biol. 24, 3820-3836. doi: $10.1111 / \mathrm{gcb} .14103$

Schmelitschek, E., French, K., and Parry-Jones, K. A. (2009). Fruit availability and utilisation by grey-headed flying foxes (Pteropodidae: Pteropus poliocephalus) in a human-modified environment on the south coast of New South Wales, Australia. Wildl. Res. 36, 592-600. doi: 10.1071/WR08169
Schneeberger, K., and Voigt, C. C. (2016). "Zoonotic viruses and conservation of bats," in Bats in the Anthropocene: Conservation of Bats in a Changing World, eds C. C. Voigt and T. Kingston (Cham: Springer International Publishing), 263-292. doi: 10.1007/978-3-319-25220-9_10

Scholesing, E., Chambon, R., Tran, A., Choden, K., Ravon, S., Epstein, J. H., et al. (2020). Patterns of foraging activity and fidelity in a southeast Asian flying fox. Mov. Ecol. 8:46. doi: 10.1186/s40462-020-00232-8

Schupp, E. W., Zwolak, R., Jones, L. R., Snell, R. S., Beckman, N. G., Aslan, C., et al. (2019). Intrinsic and extrinsic drivers of intraspecific variation in seed dispersal are diverse and pervasive. AoB PLANTS 11:lz067. doi: 10.1093/aobpla/plz067

Seltzer, C. E., Ndangalasi, H. J., and Cordeiro, N. J. (2013). Seed dispersal in the dark: Shedding light on the role of fruit bats in Africa. Biotropica 45, 450-456. doi: $10.1111 /$ btp. 12029

Shackleton, C. M., Ruwanza, S., Sinasson Sanni, G. K., Bennett, S., De Lacy, P., Modipa, R., et al. (2016). Unpacking Pandora's box: understanding and categorising ecosystem disservices for environmental management and human wellbeing. Ecosystems 19, 587-600. doi: 10.1007/s10021-015-9952-z

Shafie, N. J., Rahman, N. A., Sah, S. A. M., Rosely, N. F. N., and Sufian, M. (2014). Feeding behaviour of Cynopterus sphinx (Pteropodidae) under captive conditions. Trop. Life Sci. Res. 25, 53-59.

Shanahan, M., and Compton, S. G. (2001). "Vertical stratification of figs and figeaters in a Bornean lowland rain forest: how is the canopy different?" in Tropical Forest Canopies: Ecology and Management, eds K. E. Lindsenmair, A. J. Davis, B. Fiala, and M. R. Speight. (Springer).

Shanahan, M., Harrison, R. D., Yamuna, R., Boen, W., and Thornton, I. W. B. (2001). Colonization of an island volcano, Long Island, Papua New Guinea, and an emergent island, Motmot, in its caldera lake. V. Colonization by figs (Ficus spp.), their dispersers and pollinators. J. Biogeogr. 28, 1365-1377. doi: 10.1046/j.1365-2699.2001.2811121365.x

Sheherazade, Ober, H. K., and Tsang, S. M. (2019). Contributions of bats to the local economy through durian pollination in Sulawesi, Indonesia. Biotropica 51, 913-922. doi: 10.1111/btp.12712

Sherry, R. A., Zhou, X., Gu, S., Arnone, J. A., Schimel, D. S., Verburg, P. S., et al. (2007). Divergence of reproductive phenology under climate warming. Proc. Natl. Acad. Sci. U.S.A. 104, 198-202. doi: 10.1073/pnas.0605642104

Shilton, L. A., Altringham, J. D., Compton, S. G., and Whittaker, R. J. (1999). Old World fruit bats can be long-distance seed dispersers through extended retention of viable seeds in the gut. Proc. R. Soc. B Biol. Sci. 266:219. doi: 10.1098/rspb.1999.0625

Simmons, B. I., Vizentin-Bugoni, J., Maruyama, P. K., Cotton, P. A., Marín-Gómez, O. H., Lara, C., et al. (2019). Abundance drives broad patterns of generalisation in plant-hummingbird pollination networks. Oikos 128, 1287-1295. doi: 10. 1111/oik.06104

Simmons, N. B., and Cirranello, A. L. (2020). Bats of the World: A Taxonomic and Geographic Database. Available online at: https://batnames.org/ (accessed November 4, 2020).

Soepadmo, E., and Eow, B. K. (1977). The reproductive biology of Durio zibethinus Murr. Gard. Bull. Singap. 29, 25-33.

Soons, M. B., Brochet, A.-L., Kleyheeg, E., and Green, A. J. (2016). Seed dispersal by dabbling ducks: an overlooked dispersal pathway for a broad spectrum of plant species. J. Ecol. 104, 443-455. doi: 10.1111/1365-2745.12531

Speakman, J. R. (2001). The evolution of flight and echolocation in bats: another leap in the dark. Mammal Rev. 31, 111-130. doi: 10.1046/j.1365-2907.2001. 00082.x

Sridhara, S., McConkey, K., Prasad, S., and Corlett, R. T. (2016). "Frugivory and seed dispersal by large herbivores of Asia," in The Ecology of Large Herbivores in South and Southeast Asia Ecological Studies, eds F. S. Ahrestani and M. Sankaran (Dordrecht: Springer Netherlands), 121-150. doi: 10.1007/978-94-017-7570$0 \_5$

Sritongchuay, T., and Bumrungsri, S. (2016). Specialized and facultative nectarfeeding bats have different effects on pollination networks in mixed fruit orchards, in Southern Thailand. J. Pollinat. Ecol. 19, 98-103.

Sritongchuay, T., Bumrungsri, S., and Sripao-raya, E. (2008). The pollination ecology of the late-successional tree, Oroxylum indicum (Bignoniaceae) in Thailand. J. Trop. Ecol. 24, 477-484. doi: 10.1017/S026646740800521X

Sritongchuay, T., Gale, G. A., Stewart, A. B., Kerdkaew, T., and Bumrungsri, S. (2014). Seed rain in abandoned clearings in a lowland evergreen rain 
forest in southern Thailand. Trop. Conserv. Sci. 7, 572-585. doi: 10.1177/ 194008291400700314

Sritongchuay, T., Hughes, A. C., and Bumrungsri, S. (2019). The role of bats in pollination networks is influenced by landscape structure. Glob. Ecol. Conserv. 20:e00702. doi: 10.1016/j.gecco.2019.e00702

Sritongchuay, T., Kremen, C., and Bumrungsri, S. (2016). Effects of forest and cave proximity on fruit set of tree crops in tropical orchards in Southern Thailand. J. Trop. Ecol. 32, 269-279. doi: 10.1017/S0266467416000353

Stephenraj, D., Isaac, S. S., Kunz, T. H., and Stanley, J. A. (2010). Foraging behaviour of megachiropteran bats. Bioinfolet 7, 175-180.

Stewart, A. B., and Dudash, M. R. (2016). Differential pollen placement on an Old World nectar bat increases pollination efficiency. Ann. Bot. 117, 145-152. doi: 10.1093/aob/mcv163

Stewart, A. B., and Dudash, M. R. (2017). Flower-visiting bat species contribute unequally toward agricultural pollination ecosystem services in southern Thailand. Biotropica 49, 239-248. doi: 10.1111/btp.12401

Stewart, A. B., and Dudash, M. R. (2018). Foraging strategies of generalist and specialist Old World nectar bats in response to temporally variable floral resources. Biotropica 50, 98-105. doi: 10.1111/btp.12492

Stewart, A. B., Makowsky, R., and Dudash, M. R. (2014). Differences in foraging times between two feeding guilds within Old World fruit bats (Pteropodidae) in southern Thailand. J. Trop. Ecol. 30, 249-257. doi: 10.1017/S0266467414000042

Stier, S. C., and Mildenstein, T. L. (2005). Dietary habits of the world's largest bats: the Philippine flying foxes, Acerodon jubatus and Pteropus vampyrus lanensis. J. Mammal. 86, 719-728.

Stoner, K. E., Riba-Hernández, P., Vulinec, K., and Lambert, J. E. (2007). The role of mammals in creating and modifying seedshadows in tropical forests and some possible consequences of their elimination. Biotropica 39, 316-327. doi: 10.1111/j.1744-7429.2007.00292.x

Struebig, M. J., Harrison, M. E., Cheyne, S. M., and Limin, S. H. (2007). Intensive hunting of large flying foxes Pteropus vampyrus natunae in Central Kalimantan, Indonesian Borneo. Oryx 41, 390-393. doi: 10.1017/S0030605307000310

Tait, J., Perotto-Baldivieso, H. L., McKeown, A., and Westcott, D. A. (2014). Are flying-foxes coming to town? Urbanisation of the spectacled flying-fox (Pteropus conspicillatus) in Australia. PLoS One 9:e109810. doi: 10.1371/journal. pone.0109810

Tan, K. H., Zubaid, A., and Kunz, T. H. (2000). Fruit dispersal by the lesser dog-faced fruit bat, Cynopterus brachyotis (Muller) (Chiroptera: Pteropodidae). Malay. Nat. J. 54, 57-62.

Tanalgo, K. C., and Hughes, A. C. (2019). Priority-setting for Philippine bats using practical approach to guide effective species conservation and policy-making in the Anthropocene. Hystrix Ital. J. Mammal. 30, 74-83. doi: 10.4404/hystrix00172-2019

Tang, Z.-H., Cao, M., Sheng, L.-X., Ma, X.-F., Walsh, A., and Zhang, S.-Y. (2008). Seed dispersal of Morus macroura (Moraceae) by two frugivorous bats in Xishuangbanna, SW China. Biotropica 40, 127-131. doi: 10.1111/j.1744-7429. 2007.00307.x

Tang, Z.-H., Mukherjee, A., Sheng, L.-X., Cao, M., Liang, B., Corlett, R. T., et al. (2007a). Effect of ingestion by two frugivorous bat species on the seed germination of Ficus racemosa and F. hispida (Moraceae). J. Trop. Ecol. 23, 125-127. doi: 10.1017/S0266467406003737

Tang, Z.-H., Sheng, L.-X., Ma, X.-F., Cao, M., Parsons, S., Ma, J., et al. (2007b). Temporal and spatial patterns of seed dispersal of Musa acuminata by Cynopterus sphinx. Acta Chiropt. 9, 229-235.

Tang, Z.-H., Xu, J.-L., Flanders, J., Ding, X.-M., Ma, X.-F., Sheng, L.-X., et al. (2012). Seed dispersal of Syzygium oblatum (Myrtaceae) by two species of fruit bat (Cynopterus sphinx and Rousettus leschenaulti) in South-West China. J. Trop. Ecol. 28, 255-261. doi: 10.1017/S0266467412000156

The Plant List (2013). The Plant List. Version 1.1. Available online at: http://www. theplantlist.org/'.

Thiriet, D. (2010). Flying fox conservation laws, policies and practices in Australia - a case study in conserving unpopular species. Australas. J. Nat. Resour. Law Policy 13, 161-194.

Thomas, D. W. (1982). The Ecology of an African Savanna Fruit Bat Community: Resource Partitioning and Role in Seed Dispersal. Ph. D. Dissertation, University of Aberdeen, Aberdeen.

Toledo, S., Shohami, D., Schiffner, I., Lourie, E., Orchan, Y., Bartan, Y., et al. (2020). Cognitive map-based navigation in wild bats revealed by a new high-throughput tracking system. Science 369, 188-193. doi: 10.1126/science. aax6904

Toyama, C., Kobayashi, S., Denda, T., Nakamoto, A., and Izawa, M. (2012). Feeding behavior of the Orii's flying-fox, Pteropus dasymallus inopinatus, on Mucuna macrocarpa and related explosive opening of petals, on Okinawajima Island in the Ryukyu Archipelago, Japan. Mammal Study 37, 205-213. doi: 10.3106/041. 037.0304

Traveset, A. (1998). Effect of seed passage through vertebrate frugivores' guts on germination: a review. Perspect. Plant Ecol. Evol. Syst. 1, 151-190. doi: 10.1078/ 1433-8319-00057

Tsang, S. M. (2020). Pteropus hypomelanus. The IUCN Red List of Threatened Species. Version 2020-3. Available online at: https://www.iucnredlist.org/en (accessed December 11, 2020)

Tsang, S. M., Wiantoro, S., Veluz, M. J., Sugita, N., Nguyen, Y.-L., Simmons, N. B., et al. (2020). Dispersal out of Wallacea spurs diversification of Pteropus flying foxes, the world's largest bats (Mammalia: Chiroptera). J. Biogeogr. 47, 527-537. doi: $10.1111 /$ jbi. 13750

Tsoar, A. (2011). Foraging Movements and Navigation Capacity of Egyptian Fruit Bats (Rousettus aegyptiacus), and Their Role in Seed Dispersal. Ph. D. Dissertation, Hebrew University, Jerusalem.

Tsuji, Y., Yangozene, K., and Sakamaki, T. (2010). Estimation of seed dispersal distance by the bonobo, Pan paniscus, in a tropical forest in Democratic Republic of Congo. J. Trop. Ecol. 26, 115-118. doi: 10.1017/S0266467409990290 Tuttle, M. D. (2018). Fear of bats and its consequences. J. Bat Res. Conserv. 10, 1-4. Tuttle, M. D. (2020). A Viral Witch Hunt. Issues in Science Technology. Available online at: https://issues.org/a-viral-witch-hunt-bats/ (accessed November 11, 2020).

United Nations (2020). Geographic Regions. Statistics Division, Department of Economic and Social Affairs, United Nations. Available online at: https://unstats. un.org/unsd/methodology/m49/\#geo-regions (accessed March 10, 2020).

Utzurrum, R. C. (1995). Feeding ecology of Philippine fruit bats: patterns of resource use and seed dispersal. Symp. Zool. Soc. Lond. 67, $63-78$.

Utzurrum, R. C. B., and Heideman, P. D. (1991). Differential ingestion of viable vs nonviable Ficus seeds by fruit bats. Biotropica 23, 311-312. doi: 10.2307/2388211 van Oldenborgh, G. J., Krikken, F., Lewis, S., Leach, N. J., Lehner, F., Saunders, K. R., et al. (2020). Attribution of the Australian bushfire risk to anthropogenic climate change. Nat. Hazards Earth Syst. Sci. Discuss. doi: 10.5194/nhess-202069 [Epub ahead of print].

van Toor, M. L., O’Mara, M. T., Abedi-Lartey, M., Wikelski, M., Fahr, J., and Dechmann, D. K. N. (2019). Linking colony size with quantitative estimates of ecosystem services of African fruit bats. Curr. Biol. 29, R237-R238. doi: 10.1016/j.cub.2019.02.033

Vaz, A. S., Kueffer, C., Kull, C. A., Richardson, D. M., Vicente, J. R., Kühn, I., et al. (2017). Integrating ecosystem services and disservices: insights from plant invasions. Ecosyst. Serv. 23, 94-107. doi: 10.1016/j.ecoser.2016.11.017

Vendan, S. E., and Kaleeswaran, B. (2011). Plant dispersal by Indian flying fox Pteropus giganteus in Madurai region, India. Elixir Bio Div 30, 18101813.

Villalobos-Chaves, D., Padilla-Alvárez, S., and Rodríguez-Herrera, B. (2016). Seed predation by the wrinkle-faced bat Centurio senex: a new case of this unusual feeding strategy in Chiroptera. J. Mammal. 97, 726-733. doi: 10.1093/jmammal/ gyv222

Vincenot, C. E., Collazo, A. N., and Russo, D. (2017a). The Ryukyu flying fox (Pteropus dasymallus)-A review of conservation threats and call for reassessment. Mammal. Biol. 83, 71-77. doi: 10.1016/j.mambio.2016.11.006

Vincenot, C. E., Florens, F. B. V., and Kingston, T. (2017b). Can we protect island flying foxes? Science 355, 1368-1370. doi: 10.1126/science.aam7582

Voigt, F. A., Farwig, N., and Johnson, S. D. (2011). Interactions between the invasive tree Melia azedarach (Meliaceae) and native frugivores in South Africa. J. Trop. Ecol. 27, 355-363.

von Döhren, P., and Haase, D. (2015). Ecosystem disservices research: a review of the state of the art with a focus on cities. Ecol. Indic. 52, 490-497. doi: 10.1016/j.ecolind.2014.12.027

Watzke, S. (2006). Ressourcennutzung und Paarungssystem der Nektarivoren Flughundart Macroglossus Minimus (Pteropodidae: Macroglossinae) in WestMalaysia. Ph. D. Dissertation, Ludwig-Maximilians-Universität München, Munich. 
Wayo, K., Phankaew, C., Stewart, A. B., and Bumrungsri, S. (2018). Bees are supplementary pollinators of self-compatible chiropterophilous durian. J. Trop. Ecol. 34, 41-52. doi: 10.1017/S0266467418000019

Webala, P. W., Musila, S., and Makau, R. (2014). Roost occupancy, roost site selection and diet of straw-coloured fruit bats (Pteropodidae: Eidolon helvum) in western Kenya: the need for continued public education. Acta Chiropt. 16, 85-95. doi: 10.3161/150811014X683291

Webb, S. L. (1986). Potential role of passenger pigeons and other vertebrates in the rapid holocene migrations of nut trees. Quat. Res. 26, 367-375. doi: 10.1016/ 0033-5894(86)90096-7

Weber, N., Duengkae, P., Fahr, J., Dechmann, D. K. N., Phengsakul, P., Khumbucha, W., et al. (2015). High-resolution GPS tracking of Lyle's flying fox between temples and orchards in central Thailand. J. Wildl. Manag. 79, 957-968. doi: 10.1002/jwmg.904

Wee, A. K. S., Teo, J. X. H., Chua, J. L., Takayama, K., Asakawa, T., Meenakshisundaram, S. H., et al. (2017). Vicariance and oceanic barriers drive contemporary genetic structure of widespread mangrove species Sonneratia alba J. Sm in the Indo-West Pacific. Forests 8:483. doi: 10.3390/f8120483

Welbergen, J. A., Klose, S. M., Markus, N., and Eby, P. (2008). Climate change and the effects of temperature extremes on Australian flying-foxes. Proc. R. Soc. B Biol. Sci. 275, 419-425. doi: 10.1098/rspb.2007.1385

Welbergen, J. A., Meade, J., Field, H. E., Edson, D., McMichael, L., Shoo, L. P., et al. (2020). Extreme mobility of the world's largest flying mammals creates key challenges for management and conservation. BMC Biol. 18:101. doi: 10.1186/ s12915-020-00829-w

Welch, J. N., and Leppanen, C. (2017). The threat of invasive species to bats: a review. Mammal Rev. 47, 277-290. doi: 10.1111/mam.12099

Whittaker, R. J., and Jones, S. H. (1994). The role of frugivorous bats and birds in the rebuilding of a tropical forest ecosystem, Krakatau, Indonesia. J. Biogeogr. 21, 245-258. doi: 10.2307/2845528

Wiles, G. J. (1987). Current research and future management of Marianas fruit bats (Chiroptera: Pteropodidae) on Guam. Aust. Mammal. 10, 93-95.

Winfree, R., Williams, N. M., Dushoff, J., and Kremen, C. (2014). Species abundance, not diet breadth, drives the persistence of the most linked pollinators as plant-pollinator networks disassemble. Am. Nat. 183, 600-611. doi: $10.1086 / 675716$

Yates, K. K., Rogers, C. S., Herlan, J. J., Brooks, G. R., Smiley, N. A., and Larson, R. A. (2014). Diverse coral communities in mangrove habitats suggest a novel refuge from climate change. Biogeosciences 11, 4321-4337. doi: 10.5194/bg-114321-2014

Yuan, J. S., Himanen, S. J., Holopainen, J. K., Chen, F., and Stewart, C. N. (2009). Smelling global climate change: mitigation of function for plant volatile organic compounds. Trends Ecol. Evol. 24, 323-331. doi: 10.1016/j.tree.2009. 01.012

Zamora-Gutiérrez, V., Rivera-Villanueva, A. N., Castro-Castro, A., and AguirreGutiérrez, J. (2021). Vulnerability of bat-plant pollination interactions due to environmental change. Glob. Change Biol. doi: 10.1111/gcb.15611 [Epub ahead of print].

Zhang, W., Ricketts, T. H., Kremen, C., Carney, K., and Swinton, S. M. (2007). Ecosystem services and dis-services to agriculture. Ecol. Econ. 64, 253-260. doi: 10.1016/j.ecolecon.2007.02.024

Zhao, H. (2020). COVID-19 drives new threat to bats in China. Science 367, 1436-1436. doi: 10.1126/science.abb3088

Zwolak, R. (2018). How intraspecific variation in seed-dispersing animals matters for plants. Biol. Rev. 93, 897-913. doi: 10.1111/brv.1 2377

Conflict of Interest: The authors declare that the research was conducted in the absence of any commercial or financial relationships that could be construed as a potential conflict of interest.

Copyright (C) 2021 Aziz, McConkey, Tanalgo, Sritongchuay, Low, Yong, Mildenstein, Nuevo-Diego, Lim and Racey. This is an open-access article distributed under the terms of the Creative Commons Attribution License (CC BY). The use, distribution or reproduction in other forums is permitted, provided the original author(s) and the copyright owner(s) are credited and that the original publication in this journal is cited, in accordance with accepted academic practice. No use, distribution or reproduction is permitted which does not comply with these terms. 